\title{
A Novel Transient Glutamatergic Population Migrating from the Pallial-Subpallial Boundary Contributes to Neocortical Development
}

\author{
Anne Teissier, Amélie Griveau, Lisa Vigier, Tristan Piolot, Ugo Borello, and Alessandra Pierani \\ Centre National de la Recherche Scientifique-Unité Mixte de Recherche 7592, Institut Jacques Monod, Université Paris Diderot, 75205 Paris Cedex 13 , \\ France
}

\begin{abstract}
The generation of a precise number of neural cells and the determination of their laminar fate are tightly controlled processes during development of the cerebral cortex. Using genetic tracing in mice, we have identified a population of glutamatergic neurons generated by $D b \times 1$ expressing progenitors at the pallial-subpallial boundary predominantly at embryonic day 12.5 (E12.5) and subsequent to Cajal-Retzius cells. We show that these neurons migrate tangentially to populate the cortical plate (CP) at all rostrocaudal and mediolateral levels by E14.5. At birth, they homogeneously populate cortical areas and represent $<5 \%$ of cortical cells. However, they are distributed into neocortical layers according to their birthdates and express the corresponding markers of glutamatergic differentiation (Tbr1, ER81, Cux2, Ctip2). Notably, this population dies massively by apoptosis at the completion of corticogenesis and represents $50 \%$ of dying neurons in the postnatal day 0 cortex. Specific genetic ablation of these transient $D b x 1$-derived CP neurons leads to a $20 \%$ decrease in neocortical cell numbers in perinatal animals. Our results show that a previously unidentified transient population of glutamatergic neurons migrates from extraneocortical regions over long distance from their generation site and participates in neocortical radial growth in a non-cell-autonomous manner.
\end{abstract}

\section{Introduction}

The generation of a precise number of neurons during development is a crucial step in the formation of functional neural circuits (Kriegstein et al., 2006). In the developing cerebral cortex growth factors, regulators of the cell cycle and transcription factors intrinsic to the neocortical primordium control neurogenesis (Dehay and Kennedy, 2007; O'Leary et al., 2007). However, secretion of growth factors from signaling centers at the borders of the pallium during early stages of development and from ingrowing thalamic afferents during midcorticogenesis has been

\footnotetext{
Received Feb. 11, 2010; revised June 16, 2010; accepted June 20, 2010.

This work was supported by Agence Nationale de la Recherche Grant ANR-07-NEURO-046-01, Fondation pour le Recherche Médicale Grant INE20060306503, Association pour la Recherche sur le Cancer Grant 4940, and Ville de Paris Grant 2006 ASES 102 (A.P.). A.T. was the recipient of a Fellowship from the French Ministry of Education. A.G. was the recipient of fellowships from the French Ministry of Education and the Association pour la Recherche sur le Cancer. U.B. was the recipient of fellowships from Neuropôle de Recherche Francilien and Fondation pour la Recherche Médicale. A.P. is a Centre National de la Recherche Scientifique Investigator. We apologize to the authors of original work not cited. Because of space limitations, we cited review articles where possible. We thankF. Guillemot and A. Stoykova for providing us the E1-Ngn2/CRE mouse line, D. J. Anderson for the Ngn2 antibodies, S. Arber and T. M. Jessell for the ER81 antibodies, and T. Kaneko for anti-VGlut2 antibodies. We are grateful to the Imaging Facility for precious help with confocal microscopy. We thank V. Dubreuil for advice on fluorescent in situ hybridization and S. Karaz and A. Djemat for technical assistance. We are indebted to F. Causeret for modeling CP transient neurons distribution. We thank F. Causeret, S. Garel, M. Barber, and M. Wassef for critical reading of this manuscript. A.T., A.G., and A.P. conceived the study and wrote this manuscript. A.T. performed most of the experiments. A.G. initiated and performed part of the analysis of the mutant animals. L.V. performed some of the DAB immunohistochemistry experiments. T.P. designed the semiautomated counting method. U.B. performed the qPCR experiments. A.P. supervised the project.

Correspondence should be addressed to Alessandra Pierani, Centre National de la Recherche Scientifique-Unité Mixte de Recherche 7592, Institut Jacques Monod, Université Paris Diderot, 15 rue Hélène Brion, 75205 Paris Cedex 13, France. E-mail: pierani.alessandra@ijm.univ-paris-diderot.fr.

DOI:10.1523/JNEUROSCI.0776-10.2010

Copyright $\odot 2010$ the authors $\quad$ 0270-6474/10/3010563-12\$15.00/0
}

shown to provide an extrinsic control of neocortical growth (Dehay et al., 2001). In addition, an activity-dependent induction of programmed cell death $(\mathrm{PCD})$ contributes to a specific refinement of the number of cortical neurons at early postnatal stages (Haydar et al., 1999; Verney et al., 2000). Nevertheless, the contribution of intrinsic versus extrinsic cues in the final output of corticogenesis remains an open question.

In the mammalian neocortex, neurons organize in a laminated structure according to an "inside-out" sequence (Rakic, 1974). During development, the first generated neurons constitute the preplate $(\mathrm{PP})$, which is later split into an upper marginal zone (MZ) and a lower subplate layer (SP) by successive waves of glutamatergic neurons that form the cortical plate (CP) (Berry et al., 1964). In contrast to GABAergic interneurons, which invade the developing cortex by tangential migration, glutamatergic neurons are thought to be born locally from pallial progenitors and to mostly reach their final laminar destination via radial glia-mediated migration (Rakic, 1972; Marín-Padilla, 1998; Kriegstein and Noctor, 2004).

Glutamatergic Cajal-Retzius (CR) and subplate/pioneer cells are among the earliest generated neuronal classes populating the preplate and have been shown to play crucial roles in cortical development by controlling lamination and thalamic axons pathfinding (Meyer et al., 1998; Supèr et al., 1998; Zecevic and Rakic, 2001). CR subtypes arise from focal progenitor domains at the edges of the developing pallium and invade the preplate by tangential migration (Takiguchi-Hayashi et al., 2004; Bielle et al., 2005; Yoshida et al., 2006). Notably, both CR and SP cells mostly disappear at the end of development (Meyer et al., 1998; Supèr et al., 1998). Nevertheless, a much higher number of transient cells 
and structures appear to exist as suggested by the observation of transient markers staining (Mitrovic and Schachner, 1996; Huh et al., 1997) and transient axonal projections (Innocenti and Price, 2005). Furthermore, up to $30 \%$ of cortical cells have been described to undergo apoptosis in the CP during the first 2 postnatal weeks in rodents (Ferrer et al., 1990; Haydar et al., 1999; Verney et al., 2000). Despite these observations, the existence, disappearance, and function of cortical transient cells have so far remained elusive because of the inability to label them throughout their life.

In this paper, we characterize a previously unidentified transient population of glutamatergic neurons in the developing cortical plate that migrate tangentially from the pallial-subpallial boundary (PSB) and play a crucial role in the control of cell numbers in the neocortex.

\section{Materials and Methods}

Animals. All animals were kept in C57BL/6 background and use of mice in this study was approved by the Veterinary Services of Paris. Transient labeling of $D b \times 1$-expressing progenitors and $D b x 1$-derived early postmitotic cells was realized using the $D b x 1^{\text {nlslacz }}$ mouse line (Pierani et al., 2001). Permanent tracing of $D b x 1$-derived cells, from embryonic stages to adulthood, was performed using $D b x 1^{\text {iresCRE }}$ animals (Bielle et al., 2005) in which the coding sequence of the CRE recombinase has been inserted by homologous recombination in the $3^{\prime}$ - untranslated region of the $D b x 1$ gene and therefore expressing the CRE under the control of the $D b x 1$ promoter. These animals were crossed with either the Tau loxP-stop-loxP-MARCKSeGFP-IRES-nlslacZ or the ROSA26 loxP-stop-loxP-YFP reporter mouse lines (Srinivas et al., 2001; Hippenmeyer et al., 2005), which label exclusively postmitotic neurons and progenitors/neurons/glial lineages, respectively. A higher total number of labeled $D b \times 1$-derived neurons was observed in Dbxi ${ }^{C R E}$;Tau ${ }^{G F P-I R E S-n l s l a c Z}$ with respect to $D b x 1^{C R E}$; $R O S A 26^{Y F P}$ embryos, likely because of a higher sensitivity of CREmediated recombination and/or higher expression levels at the Tau locus. The conditional ablation of $D b \times 1$-derived cells was performed by crossing the Dbxi $1^{\text {loxP-stop-loxP-DTA }}$ mouse line (Bielle et al., 2005) with the E1-Ngn2/CRE(iresGFP) strain (Berger et al., 2004) expressing the CRE recombinase and the green fluorescent protein (GFP) under the control of the E1 enhancer element of the Ngn2 gene. Embryos and postnatal animals were genotyped by PCR using primers specific for the different alleles. For staging of animals, midday of vaginal plug was considered as embryonic day 0.5 (E0.5).

Tissue preparation, immunohistochemistry, XGal staining, and in situ hybridization. Embryos were fixed by immersion in $4 \%$ paraformaldehyde (PFA) in $0.1 \mathrm{~m}$ phosphate buffer (PB), $\mathrm{pH} \mathrm{7.2,} \mathrm{for} 2 \mathrm{~h}$ at $4^{\circ} \mathrm{C}$, and postnatal animals were anesthetized and perfused with $4 \%$ PFA in $0.1 \mathrm{M}$ PB for 10 min. Dissected brains were then rinsed in PBS for $2 \mathrm{~h}$, cryoprotected overnight in $30 \%$ sucrose in $0.1 \mathrm{M} \mathrm{PB}$, and embedded in OCT compound (Sakura). Embedded tissues were sectioned on a cryostat with a 12-14 $\mu \mathrm{m}$ for embryonic and $35 \mu \mathrm{m}$ step for postnatal stages. Fluorescent immunohistochemistry, Nissl staining, in situ hybridization, and XGal staining were performed as previously described (Bielle et al., 2005; Dubreuil et al., 2008). For 3,3'-diaminobenzidine tetrahydrochloride (DAB) staining, anti-GFP and anti- $\beta$ Gal antibodies were detected with a biotinylated secondary antibody using the Elite Vectastain ABC kit (Vector Laboratories) (see Figs. 4L, 6A-D; supplemental Figs. 2, 3, available at www.jneurosci.org as supplemental material). For DAB immunostaining subsequent to vesicular glutamate transporter 2 (VGlut2) mRNA in situ detection, the hybridization was processed in the absence of proteinase $\mathrm{K}$ treatment. The double immunohistochemistry using rabbit anti-GABA and rabbit anti-glutamate in supplemental Figure 1 (available at www.jneurosci.org as supplemental material) was performed using Zenon Alexa Fluor 647 rabbit IgG according to the manufacturer's protocol (Invitrogen). Primary antibodies produced in mice were as follows: anti-Reelin (Calbiochem; G10; 1:500), anti-Ngn2 (gift from D. J. Anderson), anti-Mash1 (BD Biosciences Pharmingen; 1:10), anti-NeuN (Euromedex; 1:400); primary antibodies produced in rabbit

\section{Table 1. Dbx1-derived neurons in the P0 cerebral cortex}

\begin{tabular}{|c|c|}
\hline & Percentage (\%) \\
\hline$\beta \mathrm{Gal}^{+} / \mathrm{DAPI}^{+}$ & $4.54 \pm 0.90$ \\
\hline $\mathrm{NeuN}^{+} / \mathrm{DAPI}^{+}$ & $87.13 \pm 2.33$ \\
\hline$\beta \mathrm{Gal}^{+} \mathrm{NeuN}^{+} / \mathrm{NeuN}^{+}$ & $4.02 \pm 0.09$ \\
\hline$\beta \mathrm{Gal}^{+} \mathrm{Glu}^{+} / \mathrm{Glu}^{+}$ & $4.49 \pm 1.16$ \\
\hline $\mathrm{BGal}^{+} \mathrm{Glu}^{+} / \mathrm{DAPI}^{+}$ & $3.99 \pm 1.04$ \\
\hline$\beta_{\mathrm{Gal}^{+}}^{+} \mathrm{GABA}^{+} / \mathrm{DAPI}^{+}$ & $0.42 \pm 0.14$ \\
\hline$\beta \mathrm{Gal}^{+} \mathrm{NeuN}^{+} / \beta \mathrm{Gal}^{+}$ & $96.97 \pm 0.05$ \\
\hline$\beta \mathrm{Gal}^{+} \mathrm{Glu}^{+} / \beta \mathrm{Gal}^{+}$ & $91.38 \pm 3.55$ \\
\hline$\beta \mathrm{Gal}^{+} \mathrm{GABA}^{+} / \beta \mathrm{Gal}^{+}$ & $7.85 \pm 0.75$ \\
\hline
\end{tabular}

Results are expressed as mean \pm SEM.

were as follows: anti-Calbindin (Swant; CB8a; 1:4000), anti-activated Caspase3 (Cell Signaling; 5A1; 1:800), anti-Cux2 (Santa Cruz; CDP M-222; 1:300), anti-GABA (Sigma-Aldrich; 1:4000), anti-glutamate (Sigma-Aldrich; 1:5000), anti-Dbx1 (gift from S. Morton and T. M. Jessell, Howard Hughes Medical Institute, Columbia University, New York, NY; 1:10,000), anti-Olig2 (Millipore; AB9610; 1:500), anti-ER81 (gift from S. Arber, Biozentrum, Basel, Switzerland, and T. M. Jessell), anti-Tbr1 (Millipore Bioscience Research Reagents; 1:4000), anti-Tbr2 (Millipore Bioscience Research Reagents; 1:8000), anti-GFP (Invitrogen; 1:2000). We also used rat anti-Ctip2 (Abcam; 1:300), chick anti-GFP (AvesLab; $1: 2000$ ), chick anti- $\beta$ Gal (Abcam; $1: 4000$ ), and guinea pig anti-VGlut2 (gift from T. Kaneko, Kyoto University, Kyoto, Japan; 1:1000). Birthdating experiments were performed on animals obtained from pregnant females injected intraperitoneally with a single dose of 5-bromodeoxyuridine (BrdU) (Sigma-Aldrich; $50 \mathrm{mg} / \mathrm{kg}$ ). BrdU staining was performed using rat anti-BrdU (Accurate Chemical; 1:400) after 5 min of 4 M HCl treatment. 4',6-Diamidino-2-phenylindole (DAPI) staining was performed using Vectashield Mounting with DAPI from Biovalley. All fluorescent secondary antibodies were purchased from Jackson ImmunoResearch. Terminal deoxynucleotidyl transferase-mediated biotinylated UTP nick end labeling (TUNEL) staining was performed according to the manufacturer's protocol (Roche).

Slice culture, transplantation experiments, and CMTMR injections. Three hundred micrometer slices of E12.5 Dbx1 ${ }^{C R E} ; R O S A 26^{Y F P}$, $D b \times 1^{C R E}$;Tau ${ }^{\text {GFPiresnlslacz }}$ or control embryos were prepared from fresh brain tissue using a vibratome and cultured for $2 \mathrm{~d}$ as previously described (Bielle et al., 2005). For grafting experiments, ventricular zone (VZ) explants were dissected from the PSB of Dbx1 ${ }^{\text {CRE }}$;Tau ${ }^{\text {GFPiresnlslacZ }}$ embryos and used to replace the VZ at the PSB at the same rostrocaudal (RC) level of control slices collected from littermate wild-type embryos. For the PSB removal experiments, the PSB was dissected out from $D b x 1^{C R E} ;$ Tau $^{\text {GFPiresnlslacZ }}$ embryos before culturing. For (5-(6)-(((4chloromethyl)benzoyl)amino)tetramethylrhodamine (CMTMR) injections, a pellet of $0.7 \mu \mathrm{m}$ tungsten beads (Bio-Rad; M-10) coated with CellTracker Orange (CMTMR) in $10 \mathrm{~mm}$ DMSO (Invitrogen) was inserted into the VZ of the PSB. After $2 \mathrm{~d}$ in vitro (DIV), slices were fixed for 45 min with $4 \%$ PFA in $0.1 \mathrm{M} \mathrm{PB}$ and rinsed for $1 \mathrm{~h}$ in PBS before immunostaining with primary antibodies in PBS, $0.2 \%$ Triton, and $1 \%$ horse serum overnight. After three washes in PBS, $0.2 \%$ Triton, and $1 \%$ horse serum, the slices were incubated overnight with secondary fluorescent antibodies in the same buffer. For immunostaining of CMTMR experiments, $100 \mu \mathrm{M}$ serial sections were prepared from each slice and incubated with different primary antibodies.

Data collection. Countings of cells labeled by immunofluorescence were performed manually on 12-14 $\mu \mathrm{m}$ sections for E11.5 to E14.5 embryonic stages and on $35 \mu \mathrm{m}$ sections for E16.5 to postnatal stages [with the exception of (1)] using the ImageJ software. Countings of cells labeled by DAB immunostaining and DAPI were performed semiautomatically on $35 \mu \mathrm{m}$ sections for E16.5 to adult stages.

(1) For cell density estimation of $\mathrm{NeuN}^{+}, \mathrm{Olig} 2^{+}$, and glutamate ${ }^{+}$ cells of the total number of DAPI ${ }^{+}$, and of $\beta \mathrm{Gal}^{+}$cells of $\mathrm{NeuN}^{+}$, glutamate $^{+}$, and $\mathrm{DAPI}^{+}$cells (Table 1 ) at postnatal day $0(\mathrm{P} 0)$, cells were manually counted in $>20$ boxes of $100 \times 100 \mu \mathrm{m}$ in the dorsolateral cortex at three rostrocaudal levels on one single $1-\mu \mathrm{m}$-thick confocal section. 
(2) For analysis of the distribution of $\beta \mathrm{Gal}^{+} \mathrm{GABA}^{-}$neurons (see Fig. $1 B)$, the whole cortical surface on coronal sections of P0 brains was divided in four mediolateral (ML) regions, labeled cells were counted in each region and normalized by square millimeter of cortical surface. Counting was performed at three RC levels.

(3) For analysis of the distribution of $\beta \mathrm{Gal}^{+} \mathrm{GABA}^{+}, \beta \mathrm{Gal}^{+} \mathrm{GABA}^{-}$, $\beta \mathrm{Gal}^{+} \mathrm{BrdU}^{+} \mathrm{GABA}^{-}$, and $\beta \mathrm{Gal}^{+}$neurons in the $\mathrm{CP}$, the thickness of the dorsolateral $\mathrm{CP}$ at three RC levels was divided into 10 bins of equal size, and cells were counted in each delineated area (see Figs. $1 C$, $2 D$; supplemental Fig. 1, available at www.jneurosci.org as supplemental material).

(4) For quantifications of cell density changes during aging, DAPI ${ }^{+}$ cells were counted in $12-18$ boxes of $100 \times 100 \mu \mathrm{m}$ for each age, arbitrarily distributed in the CP (supplemental Fig. 3, available at www. jneurosci.org as supplemental material).

(5) The kinetics of disappearance of $D b x 1$-derived cells was obtained by counting the total number of labeled cells by $\beta \mathrm{Gal}$ or yellow fluorescent protein (YFP) staining in the whole cortex on five sections of $35 \mu \mathrm{m}$ distributed along the RC axis. Regions of interest corresponding to the cortical plate were designed using free hand lines selection. As the size of counted regions varied, the number of cells were normalized by square millimeter of cortical regions. Semiautomatic image processing was realized using the ImageJ software (ImageJ; W. S. Rasband, National Institutes of Health, Bethesda, MD; http://rsb.info.nih.gov/ij/; 1997-2007). Cells segmentation was done by applying gray-level thresholding on wavelets transformed images (third wavelet coefficient image). A B-spline wavelet "à trous" was used for transformation. ImageJ watershed was used to separate joined spots. Spots containing $>8$ pixels (magnification, $5 \times$; pixel size, $1.29 \mu \mathrm{m}$ ) were counted as cells. Manual countings were also performed on each animal to control the validity of this technique. Evaluation of Dbxl-derived cells over the total number of $\mathrm{DAPI}^{+}$cells was then obtained by dividing the $\beta \mathrm{Gal}^{+}$per square millimeter by DAPI per square millimeter at corresponding stages (see Fig. 6E; supplemental Fig. 3, available at www.jneurosci. org as supplemental material).

(6) The cell density per square millimeter of glutamatergic and GABAergic populations in $\mathrm{P} 0$ and adults animals (see Fig. $6 K, L$ ) was performed by counting the $\beta \mathrm{Gal}^{+} \mathrm{GABA}^{-}$per square millimeter and $\beta \mathrm{Gal}^{+} \mathrm{GABA}^{+}$per square millimeter neurons at both ages in three coronal sections on three different animals. The evaluation of glutamatergic versus GABAergic cell density on DAPI was then normalized for DAPI per square millimeter at corresponding stages.

(7) To represent the distribution of $\beta \mathrm{Gal}^{+} \mathrm{Tbr} 1^{+} \mathrm{Reln}^{-}$neurons in a lateral view of whole-mount brains at E13.5 and E14.5 (see Fig. 4P), labeled cells were counted in 16 boxes spanning the PP/CP along the RC and $\mathrm{ML}$ axis and normalized for $1 \mathrm{~mm}$ of CP length (supplemental Table 1, available at www.jneurosci.org as supplemental material). Each region was assigned a gray value corresponding to the $\beta \mathrm{Gal}^{+} \mathrm{Tbrl}^{+}{ }^{+} \mathrm{Reln}{ }^{-}$neurons density using the gradient mesh tool in Adobe Illustrator CS3. Gray values were converted in colors following the inverted royal lookup table in Image software.

(8) For quantification of CP thickness in control and mutant animals, Nissl staining was used to delineate the cortical plate, based on the differential cell density (see Fig. $7 K-R$ ).

(9) For quantifications in $D b x 1^{D T A} ; D b x 1^{n l s L a c Z}$ control and E1-Ngn2/ $C R E ; D b x 1^{D T A} ; D b x 1^{\text {nlsLacZ }}$ triple mutant animals, the number of $\mathrm{XGal}^{+}$ cells in the CP was counted in bands that were placed over the rostrodorsal and caudolateral regions of the pallium in region-matched control and mutant sections. All measurements realized in these boxes were normalized for the number of $\mathrm{XGal}^{+}$cells per millimeter of $\mathrm{CP}$ (supplemental Fig. 4, available at www.jneurosci.org as supplemental material).

Statistical analysis. For all experiments, results have been obtained from at least three animals or three pairs of control and mutant littermates, excepted for the kinetics of Dbx1-derived cells loss in $D b \times 1^{C R E}$; $\operatorname{ROSA}_{2} 6^{Y P P}$ ( $n=1-2$ animals) (supplemental Fig. 3, available at www. jneurosci.org as supplemental material). For all experiments, the number of counted cells is indicated in Results or figure legends. For all quantifications, normal distribution was confirmed and unpaired, two-tailed $t$ test on group means were performed for statistical analysis, using Microsoft Excel software $\left({ }^{\star} p<0.05,{ }^{* *} p<0.01,{ }^{* * *} p<0.001\right)$.
Image acquisition. Bright-field images of brain sections were acquired using a color camera (Zeiss Axiocam HRc) coupled to a Zeiss Axiovert 200 microscope and immunofluorescence images using an inverted confocal microscope (Leica TCS SP5 AOBS tandem resonant scanner).

Quantitative real-time PCR. Twenty nanograms of RNA extracted from the entire pallium (including the $\mathrm{PSB})\left(\mathrm{PSB}^{+}\right)$or from pallial territories dissected dorsally to the PSB $\left(\mathrm{PSB}^{-}\right.$) at E12.5 were used for cDNA synthesized with the SuperScript VILO cDNA Synthesis kit (Invitrogen), following the manufacturer's instructions. Real-time PCR was performed on a Roche LightCycler according to the manufacturer's instructions for the SYBR Green detection kit. Primers were designed using PrimerBank (Spandidos et al., 2010) and Primer3 (Rozen and Skaletsky, 2000). The primers were verified for specificity with Primer-Blast from NCBI. Expression of each gene was calculated relative to that of the mRNA for the ribosomal protein rpS17 (Sansom et al., 2005) in the same $\mathrm{PSB}^{+}$and $\mathrm{PSB}^{-}$samples and in three independent experiments. Relative quantifications of gene expression were calculated as described by Livak and Schmittgen (2001). The PCR efficiency for each primer pair was estimated with the LightCycler software using a calibration dilution curve for each primer set. Primers used were as follows: Pax6, forward, GCAGATGCAAAAGTCCAGGTG; Pax6, reverse, CAGGTTGCGAAGAACTCTGTTT; $D b x 1$, forward, TGAAGGACTCGCAGGTGA; $D b x 1$, reverse, GGTCTGGATGGGGGTTTAGTTTT).

\section{Results}

Dbx1-derived neurons populate the neonatal cortical plate

Using permanent genetic tracing, we have previously shown that Dbx1-expressing progenitors generate Reln ${ }^{+}$Cajal-Retzius neurons residing in the MZ/layer I of the early postnatal cerebral cortex. However, Reln ${ }^{-} D b x 1$-derived neurons were also detected in the CP (Bielle et al., 2005). To further characterize Dbx1derived neurons in the $\mathrm{CP}$, we used permanent tracing in $\mathrm{P} 0$ $D b \times 1^{C R E}$;Tau ${ }^{\text {GFPiresnlslacZ }}$ brains (Fig. $1 A$ ). This reporter line has been shown to label exclusively neuronal populations (Hippenmeyer et al., 2005). We confirmed that most $D b \times 1$-derived $\beta \mathrm{Gal}^{+}$cells expressed the neuronal marker NeuN (Table 1) at P0 and none coexpressed glial markers such as Olig2 and GFAP (supplemental Fig. 1, available at www.jneurosci.org as supplemental material) (data not shown). Dbx1-derived neurons $\left(\beta \mathrm{Gal}^{+} \mathrm{NeuN}^{+}\right)$represented $4.02 \pm 0.09 \%$ of the total $\mathrm{NeuN}^{+}$ population and $4.54 \pm 0.90 \%$ of the total cells $\left(\mathrm{DAPI}^{+}\right)$in the P0 cerebral cortex (Table 1). We then analyzed their neurotransmitter phenotype. Using immunostainings for $\beta \mathrm{Gal}$ and glutamate, we found that $91.38 \pm 3.55 \%$ of $\beta \mathrm{Gal}^{+}$neurons were $\mathrm{Glu}^{+}$(Fig. $1 A, D-E^{\prime}$, Table 1). Corroborating this, we found by fluorescent in situ hybridization for the VGlut2 mRNA followed by $\beta \mathrm{Gal}^{+}$ immunostaining that the large majority of $\beta \mathrm{Gal}^{+}$in $D b \times 1^{C R E}$; Tau ${ }^{\text {GFPiresnlslacZ }}$ P0 brains unambiguously coexpressed VGlut2 $(83.6 \pm 1.06 \%)($ Fig. $1 F, G)$. At P0, Dbxl-derived Glu ${ }^{+}$neurons represented $4.49 \pm 1.16 \%$ of the total $\mathrm{Glu}^{+}$neurons and $3.99 \pm$ $1.04 \%$ of the total DAPI ${ }^{+}$cells (Table 1). Coimmunostaining for GABA revealed that only $7.85 \pm 0.75 \%$ of $\beta \mathrm{Gal}^{+}$were $^{\mathrm{GABA}}{ }^{+}$ (Fig. $1 H-I^{\prime}$ ), suggesting that $\beta \mathrm{Gal}^{+} \mathrm{Glu}^{+}$and $\beta \mathrm{Gal}^{+} \mathrm{GABA}^{+}$ cells accounted for virtually all $\beta \mathrm{Gal}^{+}$neurons labeled in the

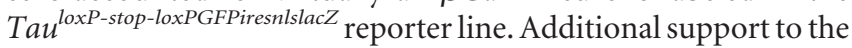
view that $\mathrm{Glu}^{+}$and $\mathrm{GABA}^{+}$cells constitute complementary subsets of $D b x 1$-derived neurons came from an absence of colabeling of glutamate with GABA in cortical neurons (supplemental Fig. 1, available at www.jneurosci.org as supplemental material). In addition, coimmunostaining of VGlut2, GABA, and YFP on P0 $D b \times 1^{C R E} ; R O S A 26^{Y F P}$ brains, a line that allows labeling of cell bodies, confirmed the colabeling of VGlut 2 in Dbx1-derived $\mathrm{YFP}^{+}$ cells and the mutually exclusive labeling of VGlut2 or GABA in cortical neurons (Fig. $1 J-L^{\prime}$ ). Thus, we parsimoniously mapped the distribution of glutamatergic $D b x 1$-derived neurons consid- 

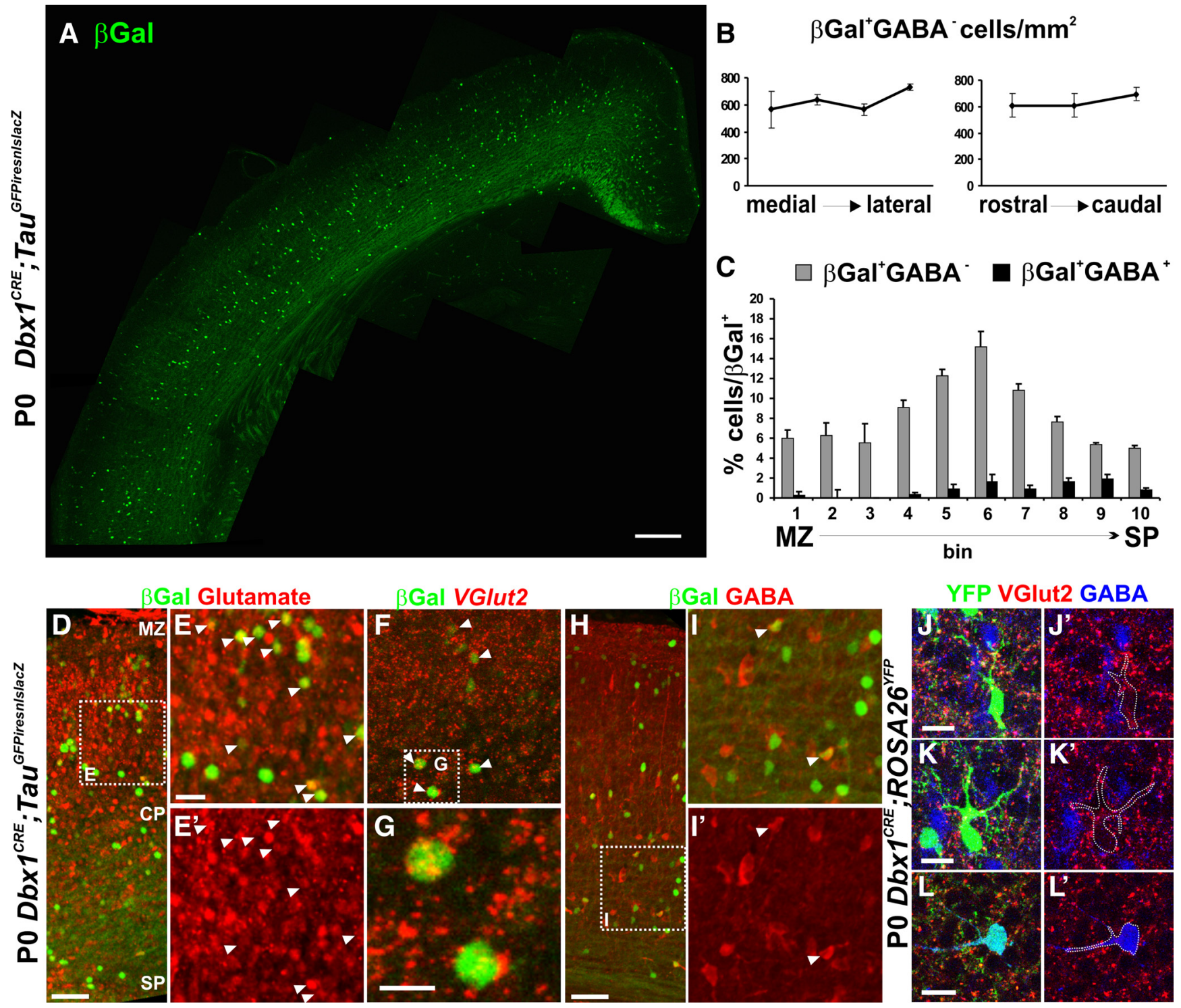

Figure 1. Distribution and neurochemical properties of Dbx 1-derived neurons in the cortical plate. $A$, Immunohistochemistry for $\beta G$ al on coronal sections of PO Dbx ${ }^{C R E} ; T a u^{G F P i r e s n l s l a c Z}$ animals shows the distribution of Dbx1-derived neurons in the neocortex. $\boldsymbol{B}$, Graphs show the homogeneous distribution of $\beta \mathrm{Gal}{ }^{+} \mathrm{GABA}{ }^{-}$neurons per square millimeter along the mediolateral and rostrocaudal axis (see Materials and Methods). C, Histogram shows the distribution of $\beta \mathrm{Gal}^{+} \mathrm{GABA}{ }^{-}$and $\beta \mathrm{Gal}{ }^{+} \mathrm{GABA}{ }^{+}$neurons relative to total number of $\beta \mathrm{Gal}{ }^{+}$neurons (in percentage) in the dorsolateral neocortex divided

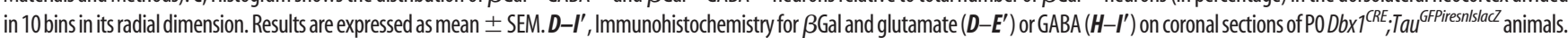

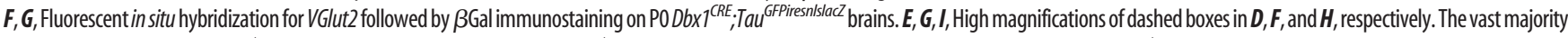
of $D b x 1$-derived neurons are Glu ${ }^{+}(91.38 \pm 3.55 \% ; n=743$ of 813$)$ or VGlut2 ${ }^{+}(83.6 \pm 1.06 \% ; n=98$ of 116$)$, whereas a small percentage are GABA ${ }^{+}(7.85 \pm 0.75 \% ; n=108$ of 1380$)$ or VGlut2 ${ }^{-}(6.3 \pm$

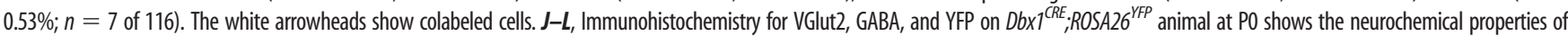
Dbx1-derived cells in the (P. Many of the YFP ${ }^{+}$cells express VGlut2 ${ }^{+}$but not GABA $\left(J-K^{\prime}\right)$. Conversely, the YFP ${ }^{+}$GABA ${ }^{+}$cells are not labeled with VGlut2 $\left(\boldsymbol{L}, \boldsymbol{L}^{\prime}\right)$. Images in $J-\boldsymbol{L}^{\prime}$ represent a $1-\mu \mathrm{m}$-thick confocal plane. Scale bars: $\boldsymbol{A}, 200 \mu \mathrm{m} ; \boldsymbol{D}, \boldsymbol{E}, 50 \mu \mathrm{m} ; \boldsymbol{F}, \boldsymbol{J}, \boldsymbol{K}, \boldsymbol{L}, 20 \mu \mathrm{m} ; \boldsymbol{G}, 10 \mu \mathrm{m}$.

ering them as $\beta \mathrm{Gal}^{+} \mathrm{GABA}^{-}$neurons. Quantification of the number of $\beta \mathrm{Gal}^{+} \mathrm{GABA}^{-}$neurons at $\mathrm{P} 0$ at three RC levels and along the entire ML axis showed that they distributed homogeneously throughout the cortex (Fig. $1 B$ ). We also specifically quantified $\beta \mathrm{Gal}^{+} \mathrm{GABA}^{-}$neurons in motor, somatosensory, and visual cortex and confirmed that their number does not differ significantly between primary cortical areas (data not shown). Nevertheless, quantifications revealed that both $\beta \mathrm{Gal}^{+} \mathrm{GABA}^{+}$and $\beta \mathrm{Gal}^{+} \mathrm{GABA}^{-}$populations preferentially positioned in deep cortical layers (Fig. $1 C$ ), suggesting an early birthdate for $D b x 1$-derived neurons in the CP.

We conclude that, in addition to CR cells in layer I, Dbx1derived neurons in the neonatal CP include a major population of glutamatergic neurons and a minor population of GABAergic neurons. The glutamatergic population homogeneously distributes in cortical territories and represents $\sim 4 \%$ of the total number of cortical cells at P0.

$D b x 1$-derived neurons are born during early stages of neurogenesis and distribute in the $\mathrm{CP}$ according to their birthdates

To study the precise timing of generation and its relationship to the laminar distribution of Dbx1-derived CP neurons, we performed BrdU injections at different embryonic stages and analyzed P0 Dbxi ${ }^{C R E}$;Tau ${ }^{\text {GFPiresnlslacZ }}$ brains by coimmunostaining for $\beta \mathrm{Gal}, \mathrm{GABA}$, and BrdU (Fig. $2 A-D$ ). Quantifications revealed that $\beta \mathrm{Gal}^{+} \mathrm{GABA}^{-}$neurons were born between E11.5 and E16.5 with $51.99 \pm 1.89 \%$ of the cells being generated at E12.5 
$\mathrm{E} 10.5 \rightarrow \mathrm{PO} \mathrm{E} 12.5 \rightarrow \mathrm{PO} \mathrm{E} 14.5 \rightarrow \mathrm{PO}$

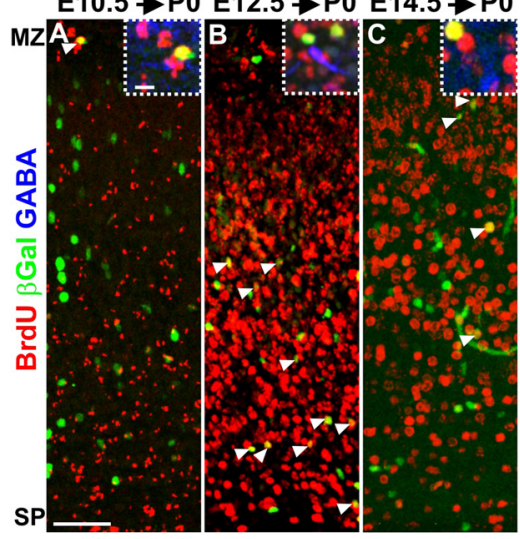

D
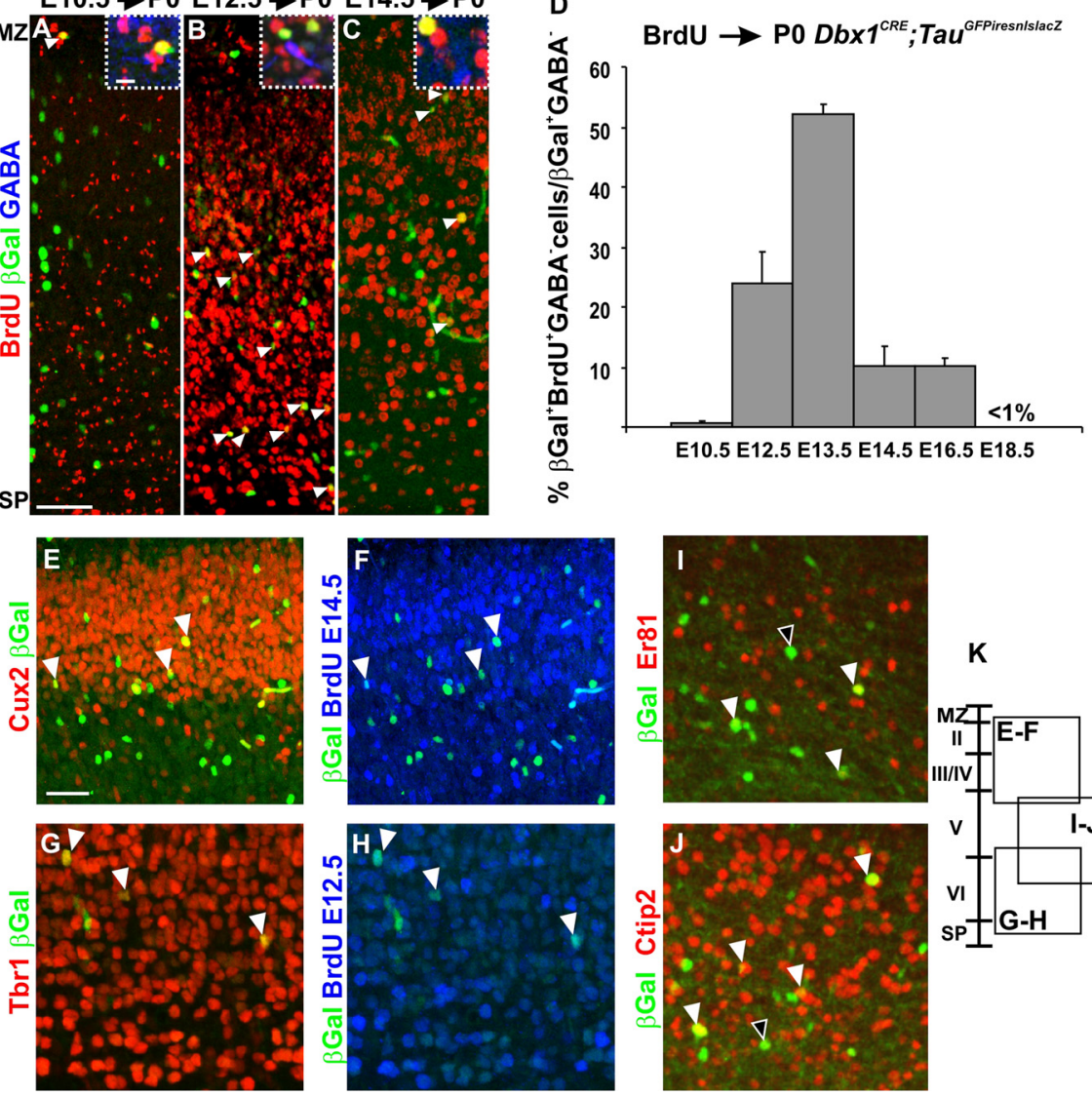

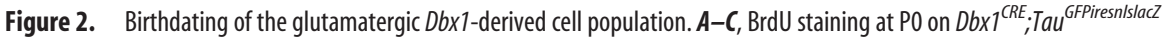
animals after a pulse shows that $\beta \mathrm{Gal}{ }^{+}$neurons born at E10.5 are positioned in the $\mathrm{MZ}(\boldsymbol{A})$; those born at E12.5, in deep layers $(\boldsymbol{B})$; and those born at E14.5, in more superficial layers ( $C$ (white arrowheads). The dashed boxes in $A-C$ are high magnifications of $\beta \mathrm{Gal}^{+} \mathrm{BrdU}^{+} \mathrm{GABA}{ }^{-}$neurons used for quantification in $\boldsymbol{D}$. $\boldsymbol{D}$, Graph represents the percentage of $\beta \mathrm{Gal}{ }^{+} \mathrm{BrdU}^{+} \mathrm{GABA}^{-} /$total $\beta \mathrm{Gal}^{+}{ }_{\mathrm{GABA}}^{-}$neurons after a pulse of BrdU at different embryonic stages and analyzed at P0. Glutamatergic Dbx1-derived neurons in the (P are mainly born between E11.5 $(24.09 \pm 5.17 \% ; n=19$ of 78$)$ and E14.5 $(10.24 \pm 3.07 \% ; n=54$ of 527$)$, with a peak at E12.5 (51.99 $\pm 1.89 \% ; n=79$ of 152$)$. Results are expressed as mean \pm SEM. $\boldsymbol{E}-\boldsymbol{H}, \beta \mathrm{Gal}{ }^{+}$neurons are predominantly $\mathrm{Tbr}^{+}(\boldsymbol{G})$ and $\mathrm{Cux2}^{+}(\boldsymbol{E})$ when born at E12.5 $(\boldsymbol{G}, \boldsymbol{H})$ and E14.5 $(\boldsymbol{E}, \boldsymbol{F})$, respectively (BrdU in blue). $\boldsymbol{I}, \boldsymbol{J}$, Some of $\beta G$ al ${ }^{+}$neurons positioned in layer $V$ express ER81 $(\boldsymbol{I})$ or Ctip2 $(\boldsymbol{J})$. The black and white arrowheads show single- and double-labeled cells, respectively. $\boldsymbol{K}$, Diagram represents the positions where the respective images have been taken in the dorsolateral cortex of P0 $D b \times T^{T R E} ;$ Tau ${ }^{G F P i r e s n l s l a c z}$ animals. Scale bars: $A, E, 50 \mu \mathrm{m} ; A$, boxed region, $10 \mu \mathrm{m}$.

(Fig. $2 D$ ). $\beta \mathrm{Gal}^{+} \mathrm{GABA}^{-}$neurons were found along the radial dimension of the CP but preferentially $(\sim 40 \%)$ in layer V (Fig. $1 C$; supplemental Fig. 1, available at www.jneurosci.org as supplemental material). The precise distribution of $\beta \mathrm{Gal}^{+} \mathrm{BrdU}^{+}$ $\mathrm{GABA}^{-}$cells in the CP after a pulse at each age is plotted in supplemental Figure 1 (available at www.jneurosci.org as supplemental material). When BrdU injection was performed at E10.5, $\beta \mathrm{Gal}^{+} \mathrm{BrdU}^{+} \mathrm{GABA}^{-}$cells were only detected in the MZ, corresponding to $\mathrm{CR}$ neurons (Fig. 2A). After injection at E12.5, $\beta \mathrm{Gal}^{+} \mathrm{BrdU}^{+} \mathrm{GABA}^{-}$cells were mainly distributed in deep layers (Fig. 2 B), whereas those generated at E14.5 were positioned in superficial layers (Fig. 2C). To assess whether their position in the $\mathrm{CP}$ was associated with a laminar fate, we performed immunostaining with Tbr1, Cux2 and ER81 or Ctip2 (markers of deep layers, superficial layers, and of subpopulations of layer $\mathrm{V}$ glutamatergic neurons, respectively) (Molyneaux et al., 2007). Double labeling with $\beta \mathrm{Gal}^{+}$was observed for all four markers (Fig. $2 E, G, I, J)$, therefore suggesting that $D b x 1$-expressing progenitors generate glutamatergic neurons fated to all layers. Moreover, triple immunostaining of $\beta \mathrm{Gal}$ with Tbr 1 or Cux 2 on BrdU injection at E12.5 and E14.5, respectively, revealed that Dbx1-derived neu-
$\mathbf{K}$

rons are fated to deep and superficial layers according to their birthdates (Fig. $2 E-H)$. Thus, the glutamatergic $D b \times 1$ derived population is generated with a strong peak at E12.5 and distributes predominantly in deep cortical layers according to its birthdate.

\section{Glutamatergic Dbx1-derived CP neurons are generated by progenitors at the PSB}

The $D b x 1$ gene was shown to be specifically expressed in the ventricular zone of the ventral pallium (VP) at the PSB with a caudal ${ }^{\text {high }}$ rostral ${ }^{\text {low }}$ gradient, in the septum and in the preoptic area (POA)/anterior entopenduncular area (AEP) (Yun et al., 2001; Medina et al., 2004; Bielle et al., 2005; Hirata et al., 2009). We previously reported that $D b x 1$-expressing progenitors at the PSB generate Reln ${ }^{+}$CajalRetzius neurons between E10.5 and E11.5 (Bielle et al., 2005). We also observed that the caudal PSB appeared to give rise to numerous Reln ${ }^{-}$cells invading the dorsal pallium tangentially at E12.5 both in the preplate and intermediate zone (IZ)/ subventricular zone (SVZ) (Bielle et al., 2005). To characterize the site of origin of CP Dbx1-derived neurons, we used immunohistochemistry for Ngn2, a marker of pallial progenitors fated to the glutamatergic lineage, and Mash1, a marker of subpallial progenitors at E12.5 (Guillemot, 2005). We confirmed that Dbx1 is expressed in pallial Ngn $2{ }^{+}$Mash $1{ }^{-}$progenitors at the PSB in both E11.5 and E12.5 telencephalons, whereas $\mathrm{Dbx}^{+}{ }^{+}$progenitors in the subpallium coexpress Mash1 (Fig. $3 A, B)$ (data not shown). Quantitative PCR (qPCR) analysis using RNA extracted from the whole pallium $\left(\mathrm{PSB}^{+}\right)$or the pallium dorsal to the PSB (PSB ${ }^{-}$) of E12.5 embryos confirmed the absence of $D b x 1$ expression in other pallial regions than the PSB/VP (Fig. 3C).

To label progenitors and early postmitotic $D b x 1$-derived neurons, we traced them using $D b x 1^{\text {nlsLacz/+ }}$ embryos (Pierani et al., 2001; Bielle et al., 2005) and performed coimmunostaining of $\beta \mathrm{Gal}$ with Tbr2 and Tbr1, two genes sequentially expressed during the differentiation of glutamatergic neurons (Englund et al., 2005). In E12.5 embryos, more $\beta \mathrm{Gal}^{+}$cells were detected at the caudal PSB than at the rostral PSB correlating with the number of $D b x 1$-expressing progenitors (Fig. $3 D-K$ ). Many $\beta \mathrm{Gal}^{+}$cells in the VZ and most of those located at the basal VZ/SVZ at both rostral and caudal PSB coexpressed Tbr2 (Fig. 3D-G). In addition, all $\beta \mathrm{Gal}^{+}$cells in the postmitotic compartment expressed Tbr1 (Fig. $3 H-L$ ). Several $\beta \mathrm{Gal}^{+} \mathrm{Tbr}^{+}{ }^{+} \mathrm{Reln}^{+} \mathrm{CR}$ neurons were observed in the lateral MZ at rostral levels but very few at caudal levels (Fig. $3 J, K$, black arrowheads). At this stage, $\beta \mathrm{Gal}^{+}$ Tbr $1^{+}$Reln ${ }^{-}$neurons in the lateral PP were oriented parallel to the pial surface, suggesting their tangential migration through the PP layer (Fig. $3 J, K$ ) (see also Fig. $4 A$ ). In the dorsal pallium, however, very few Tbr $1^{+}$Reln ${ }^{-}$Dbxl-derived neurons were ob- 

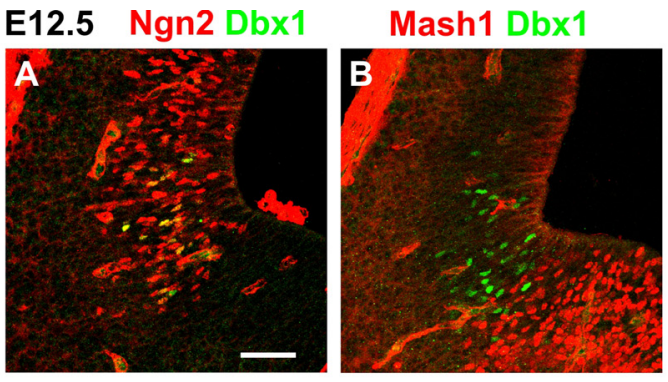

C

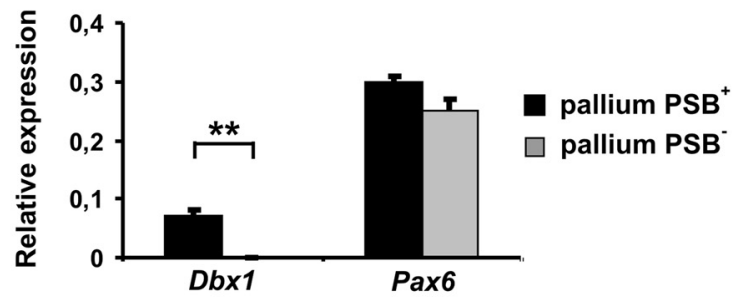

E12.5 Dbx $1^{\text {nILLacZ/+ }}$
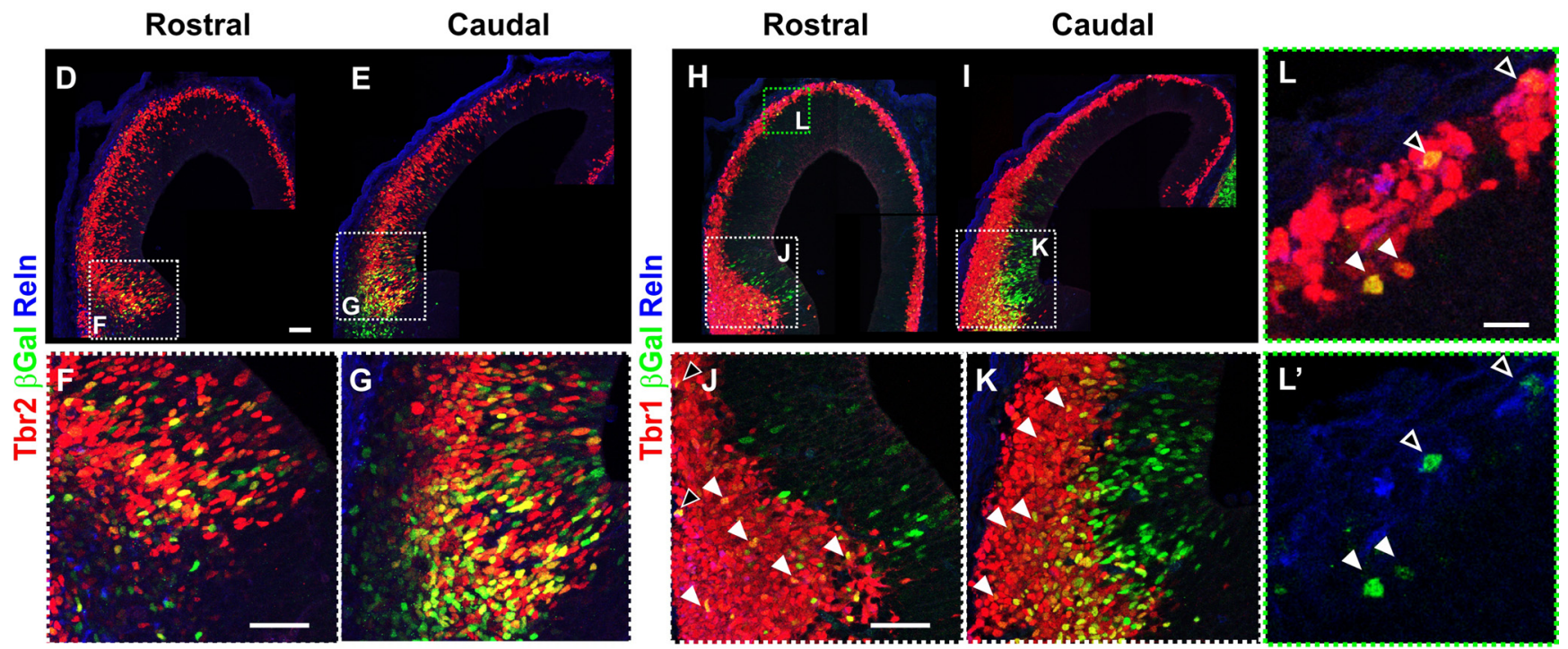

Figure 3. Dbx1-expressing progenitors at the PSB generate glutamatergic neurons at early stages of development. $A, B$, Immunostaining for Dbx1 on E12.5 coronal sections show that $D b x 1$-expressing progenitors at the PSB are pallial since they all express Ngn2 $(\boldsymbol{A})$ but not Mash $1(\boldsymbol{B})$. $\boldsymbol{C}$, Graphs represent the expression value ratios of the Dbx1 and Pax6 genes relative to that of the ribosomal protein $r p S 17$ (see Materials and Methods) in RNA samples extracted from the entire pallium including the PSB (pallium $\mathrm{PSB}^{+}$) and from pallial territories dissected dorsally to the PSB (pallium $\mathrm{PSB}^{-}$). The values represent the mean of a triplicate $\left(\right.$ mean $\pm S D ;{ }^{* *} p=0.0021$ for $\left.D b x 1\right)$. The results show the absence of $D b x 1 \mathrm{mRNA}$ expression in the pallium PSB ${ }^{-}$sample, whereas Pax 6 expression is slightly reduced because of its higher expression at the PSB. $\boldsymbol{D}-\boldsymbol{L}^{\prime}$, Immunostaining for $\beta G$ al $\left(\boldsymbol{D}-\boldsymbol{L}^{\prime}\right)$, Tbr2 (D-G), Tbr1 (H-L), and Reln $\left(\boldsymbol{D}-\boldsymbol{L}^{\prime}\right)$ on coronal sections of E12.5 Dbx $7^{n / L L a c z /+}$ embryos. $\boldsymbol{F}, \mathbf{G}, \boldsymbol{J}$, and $\boldsymbol{K}$ are high magnifications of the dashed white boxes in $\boldsymbol{D}, \boldsymbol{E}, \boldsymbol{H}$, and $\boldsymbol{I}$, respectively. $\boldsymbol{L}, \boldsymbol{L}^{\prime}$, High magnification of green dashed boxin $\boldsymbol{H}$. More $\beta G$ al ${ }^{+}$cells are detected at the caudal than at the rostral PSB (compare $\boldsymbol{F}$ with $\boldsymbol{G}$ and $\boldsymbol{J}$ with $\boldsymbol{K}$ ). The vast majority of $\beta G$ al ${ }^{+}$neurons express Tbr2 at the basal VZ/SVZ $(\boldsymbol{D}-\boldsymbol{G})$ and all express Tbr1 in the mantle zone $(\boldsymbol{H}-\boldsymbol{L}$, white and black arrowheads in $\boldsymbol{J}, \boldsymbol{K}) . \beta \mathrm{Gal}{ }^{+}{ }^{+}$br $1^{+}$Reln ${ }^{+}$cells are detected in the lateral and dorsolateral rostral cortex (black arrowheads in $J$, and $L_{,} \boldsymbol{L}^{\prime}$, respectively) but not in the lateral caudal cortex $(\boldsymbol{K})$. However, the vast majority of $\beta G$ Gal ${ }^{+}$cells in the lateral cortex are Tbr1 ${ }^{+}$Reln ${ }^{-}\left(J-L^{\prime}\right.$, white arrowheads) and few $\mathrm{Tbr}^{+}{ }^{+}$Reln ${ }^{-}$cells are observed in the dorsal pallium $\left(L, L^{\prime}\right.$, white arrowheads) at this stage. ${ }^{* *} p<0.01, t$ test. Scale bars: $A, D, F, J, 50 \mu \mathrm{m} ; L, 20 \mu \mathrm{m}$.

served at this stage (Fig. $3 L, L^{\prime}$ ). No $\beta \mathrm{Gal}^{+} \mathrm{Calbindin}^{+}$interneurons, shown to be the phenotype of POA Dbxl-derived interneurons migrating into the amygdala (Hirata et al., 2009), were detected in the pallium of $D b x 1^{\text {nlsLacz/+ }}$ animals (data not shown). Together with the absence of generation of GABAergic neurons in PSB explant cultures (Bielle et al., 2005), our results show that $D b \times 1$-expressing progenitors at the PSB generate exclusively glutamatergic cells at E12.5 in a caudal ${ }^{\text {high }}$ rostral $^{\text {low }}$ gradient and suggest that the caudal PSB generate mostly Reln ${ }^{-}$ neurons. These results also confirm the focal expression of the $D b x 1$ gene at the PSB and exclude low levels of expression in the dorsal pallium.

Glutamatergic $D b x 1$-derived neurons migrate tangentially to invade the cortical plate

Since $\beta$ Gal labeling is transient in $D b x 1^{n l s L a c z /+}$ animals, we used permanent labeling in $D b x 1^{C R E} ; R O S A 26^{Y F P}$ and $D b x 1^{C R E}$; Tau ${ }^{\text {GFPiresnlslacZ }}$ animals to follow Dbxl-derived neurons at later developmental stages. In E12.5 Dbxi ${ }^{C R E} ; R O S A 26^{Y F P}$ embryos, a deep stream of $\mathrm{YFP}^{+} \mathrm{Tbr}^{+}$cells emerging from the PSB and showing a typical morphology of migrating cells was observed in the lateral and dorsolateral pallium (Fig. $4 A-D^{\prime}$ ). By E14.5, tan- gentially oriented $\mathrm{YFP}^{+}$cells were present in the PP/CP and IZ/ SVZ and reached the dorsal pallium (Fig. $4 E-H$ ). At this stage, several $\mathrm{YFP}^{+}$cells in the IZ expressed VGlut2 (Fig. $4 E-F 3^{\prime}$ ) or GABA (Fig. $4 G-H^{\prime}$ ). Moreover, $\mathrm{YFP}^{+} \mathrm{Reln}^{+}$cells, corresponding to CR cells, and $\mathrm{YFP}^{+} \mathrm{GABA}^{+}$neurons appeared to account for all $D b \times 1$-derived cells migrating in the $\mathrm{MZ}$ at this stage (Fig. $4 E, G)$ (data not shown). Glutamatergic $\mathrm{YFP}^{+} \mathrm{VGlut}^{+}$and $\mathrm{YFP}^{+} \mathrm{Tbr}^{+}$cells were also found radially oriented (Fig. $4 E, F 1, F 1^{\prime}$; supplemental Fig. 2 , available at www.jneurosci.org as supplemental material) likely in the process of entering the lower CP. These results suggest that glutamatergic $\left(\mathrm{Reln}^{-}\right) \mathrm{Db} \times 1-$ derived neurons are tangentially migrating through the nascent $\mathrm{CP}$ and the IZ/SVZ but not the MZ. Similar migratory routes were observed using Dbxi ${ }^{C R E}$; Tau ${ }^{\text {GFPiresnlslacZ }}$ embryos at E13.5 and E14.5 (supplemental Fig. 2, available at www.jneurosci.org as supplemental material; Fig. $4 I-L$ ). We confirmed the glutamatergic phenotype of $D b \times 1$-derived neurons in the $\mathrm{IZ}$ and $\mathrm{CP}$ using in situ hybridization for the vesicular glutamate transporter VGlut2 mRNA followed by anti- $\beta$ Gal immunostaining (Fig. $4 L-O$ ). Quantification of the number of $D b x 1$-derived $\beta \mathrm{Gal}^{+} \mathrm{Tbr}{ }^{+}{ }^{+}$Reln ${ }^{-}$ neurons in $D b x 1^{C R E}$;Tau ${ }^{\text {GFPiresnlslacz }}$ embryos between E13.5 and E14.5 (Fig. 4P) confirmed a progressive increase in the dorsal CP at 


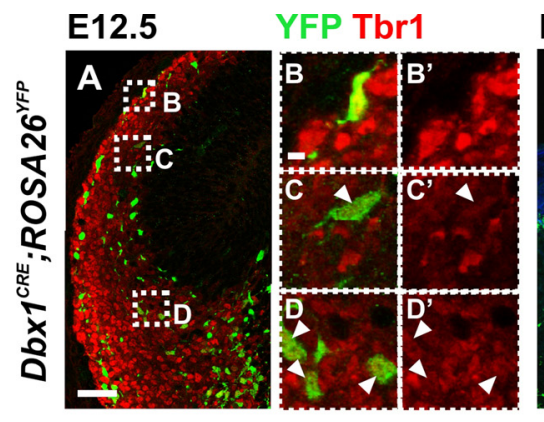

E14.5

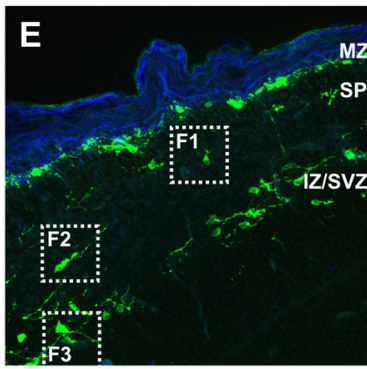

Tbr1 $\beta$ Gal Reln

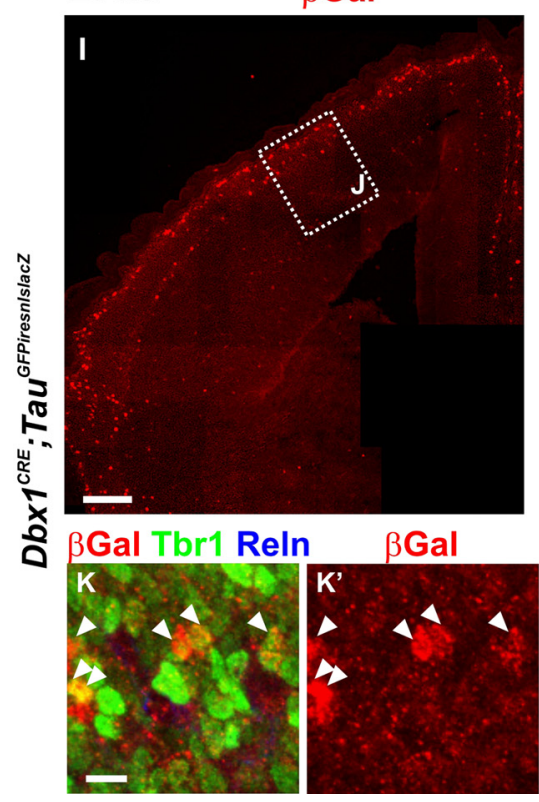

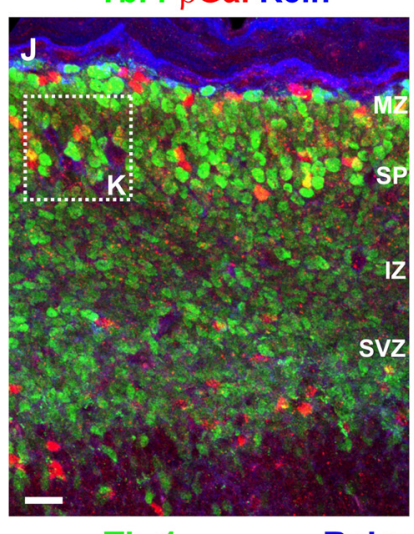

Tbr1

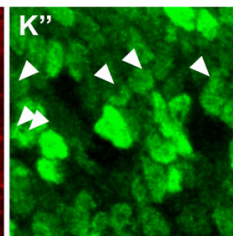

Reln

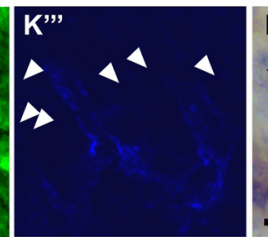

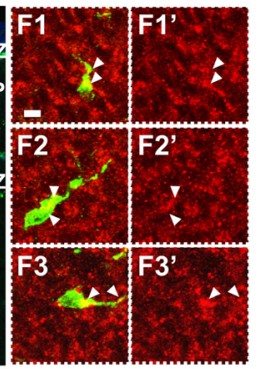
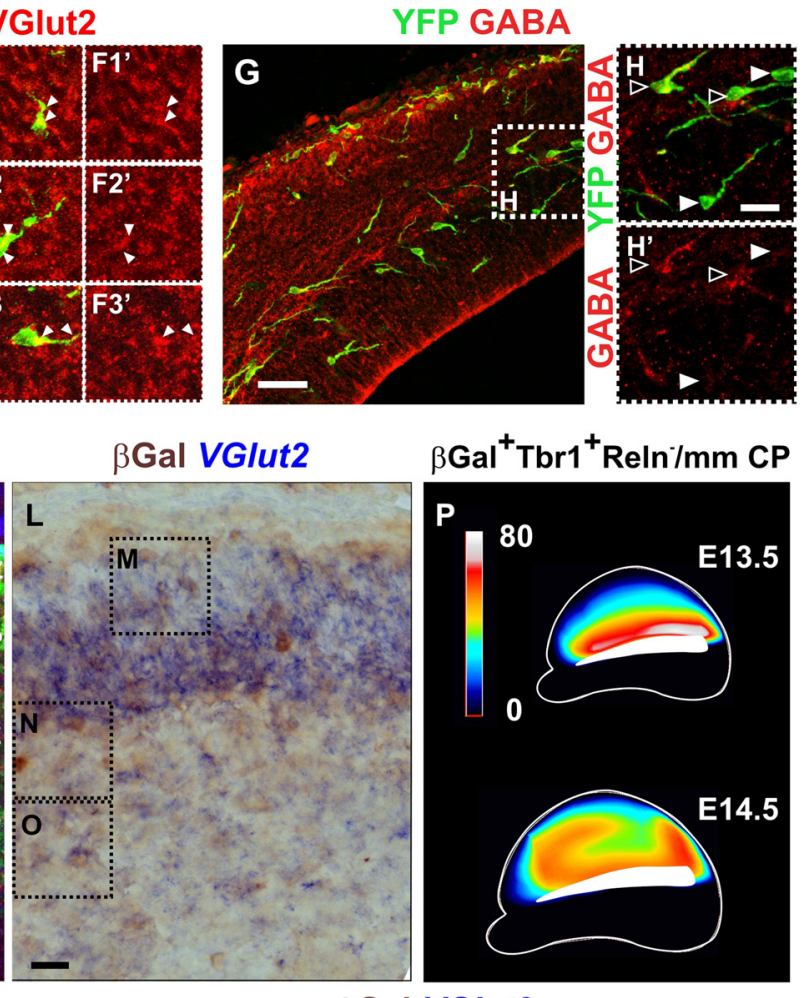

$\beta \mathrm{GaI}^{+}{ }^{+} \mathrm{Tbr}^{+}{ }^{+}$Reln $/ \mathrm{mm}$ CP

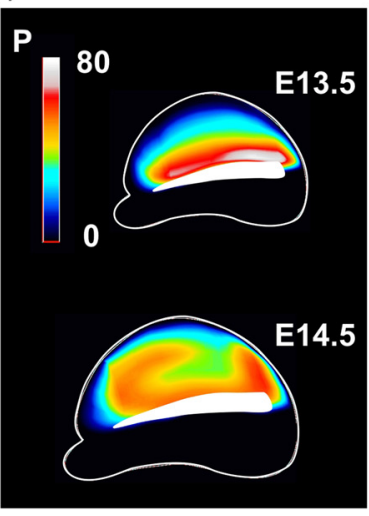

$\beta$ Gal VGlut2
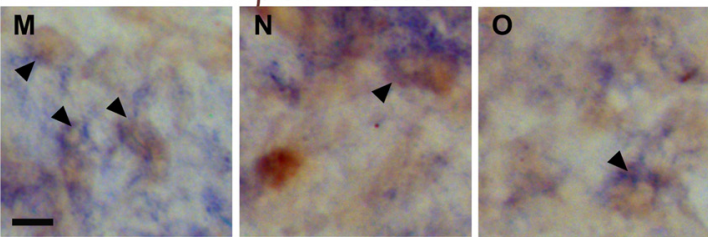

Figure 4. Dbx1-derived glutamatergic neurons present the morphology of tangentially migrating cells and progressively populate the entire pallium by E14.5. $A-D^{\prime}$, Immunostaining for YFP and Tbr1 on coronal sections of E12.5 Dbx $7^{C R E} ; R O S A 26^{Y F P}$ animals shows a deep stream of YFP ${ }^{+}$Tbr $^{+}{ }^{+}$cells emerging from the PSB $\left(\boldsymbol{D}, \boldsymbol{D}^{\prime}\right)$ and showing a typical morphology of migrating cells up to the lateral and

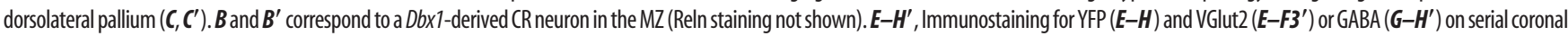

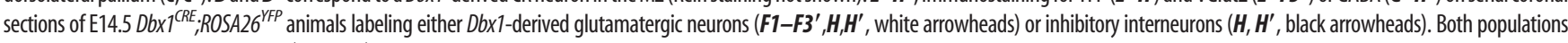

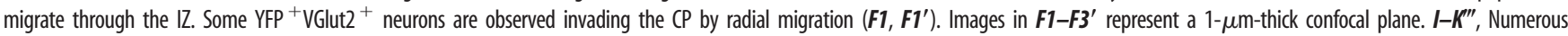

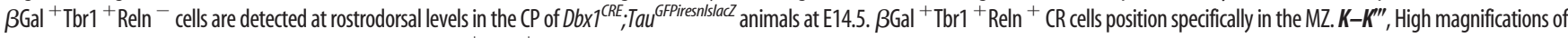
boxed region in $\boldsymbol{J} . \boldsymbol{K}^{\prime}-\boldsymbol{K}^{\prime \prime \prime}$ show single-channel images. $\beta \mathrm{Gal}{ }^{+} \mathrm{Tbr} 1^{+}$Reln ${ }^{-}$cells are distributed in the dorsal CP by E14.5 (white arrowheads). $\mathbf{L}-\mathbf{0}, \mathbf{I m m}$ monostaining for $\beta G$ Gal after in situ hybridization with a VGlut2 mRNA probe shows double-labeled cells in the IZ, SP, and CP of E14.5 Dbx $1^{\text {CRE }}$; Tau ${ }^{G F P i r e s n l s l a c Z}$ rostrodorsal cortices. $\boldsymbol{M}$ - $\mathbf{0}$, High magnifications of boxed regions in $\boldsymbol{L}$. $\boldsymbol{P}$, Schematic representation of the distribution of $\beta \mathrm{Gal}^{+} \mathrm{Tbr}^{+}{ }^{+}$Reln ${ }^{-}$neurons in the CP of E13.5 and E14.5 Dbx $1^{\text {CRE. }}$;Tau ${ }^{\text {GFPiresnlslacZ }}$ cortices (lateral view) (for values, see supplemental Table 1, available at www.jneurosci.org as supplemental material). Scale bars: I, $100 \mu \mathrm{m} ; \boldsymbol{A}, \boldsymbol{E}, \mathbf{G}, 50 \mu \mathrm{m} ; \boldsymbol{J}, \mathbf{L}, 20 \mu \mathrm{m} ; \boldsymbol{F 1}, \boldsymbol{K}, \boldsymbol{M}, 10 \mu \mathrm{m}$.

both rostral and caudal levels (Fig. $4 I-K, P$ ) and that many of the $D b x 1$-derived neurons in the $\mathrm{CP}$ are glutamatergic at this stage. The schematic representation of the distribution of $\beta \mathrm{Gal}^{+} \mathrm{Tbr} 1^{+}$Reln neurons in the CP also showed that the number of $D b x 1$-derived glutamatergic neurons appeared to increase at the rostral PSB at E14.5, suggesting a caudal-to-rostral (along the PSB), in addition to a lateral-to-dorsal, trajectory of migration of these cells (Fig. $4 P$; supplemental Table 1, available at www.jneurosci.org as supplemental material, for values).

To confirm the origin and tangential migration of Dbx1derived Tbr ${ }^{+}{ }^{\text {Reln }}{ }^{-}$neurons, we grafted PSB explants of E12.5 $D b \times 1^{C R E} ;$ Tau $^{\text {GFPiresnlslac Z }}$ embryos onto the PSB of WT slices. After 2 DIV culture, $\beta \mathrm{Gal}^{+} \mathrm{Tbr}^{+}{ }^{+}$Reln ${ }^{-}$neurons were detected in the lateral and dorsal pallium (Fig. $5 A-D^{\prime \prime}$ ). In contrast, when the PSB was removed from E12.5 Dbxi ${ }^{C R E} ; T_{a u}{ }^{\text {GFPiresnlslac } Z}$ slices and cultured for $2 \mathrm{~d}$, almost exclusively $\beta \mathrm{Gal}^{+} \mathrm{Tbr}^{+}{ }^{+} \mathrm{Reln}^{+} \mathrm{CR}$ cells were detected in the dorsal pallium correlating with their earlier birthdate and migration into the dorsal pallium from the PSB before its removal or from the remaining septum (Fig. $5 E-H^{\prime \prime}$ ). Finally, we inserted a bead coated with CellTracker Orange (CMTMR) at the PSB on E12.5 coronal and sagittal sections of Dbx ${ }^{C R E}$;ROSA26 $6^{Y F P}$ embryos (Fig. $\left.5 I-K^{\prime \prime \prime}\right)$ (data not shown). After 2 DIV, we observed colabeling of CMTMR/YFP with Tbr1 but not with GABA in cells migrating toward the dorsal pallium (Fig. $5 I, J^{\prime \prime}, K-K^{\prime \prime \prime}$, respectively).

Together, our data show that $D b x 1$-expressing progenitors at the PSB generate, in addition to Tbr $1{ }^{+}$Reln ${ }^{+}$CR cells between E10.5 and E11.5, a population of glutamatergic Tbr ${ }^{+}$Reln ${ }^{-}$ neurons at E12.5, which migrate tangentially from caudal-torostral along the PSB and from lateral-to-dorsal to populate the entire developing cortex by E14.5.

\section{Massive apoptotic cell death of CP Dbx1-derived} glutamatergic neurons in the postnatal cortex

We next examined the distribution of the CP Dbx1-derived neurons in adult $D b x 1^{C R E}$; Tau ${ }^{\text {GFPiresnlslacZ }}$ brains. Surprisingly, the number of $\beta \mathrm{Gal}^{+}$cells was dramatically decreased compared with P0 (Fig. $6 A-D$ ). We quantified the total number of $D b \times 1$ derived neurons at different embryonic and postnatal stages 
taking into account the decrease in cell density $\left(\beta \mathrm{Gal}^{+} / \mathrm{DAPI}^{+}\right.$nuclei) (for methods, see supplemental Fig. 3, available at www.jneurosci.org as supplemental material). We observed an increase in the percentage of Dbx1-derived neurons between E16.5 and P0 in the CP, whereas a strong decrease was detected between $\mathrm{P} 0$ and P8 (Fig. 6E). Similar results were obtained using two additional reporter mouse lines, namely $D b \times 1^{C R E} ; \beta a c t i n: l a c Z$ and $D b x 1^{C R E} ; R O S A 26^{Y F P}$, which labels $D b \times 1$ derived neurons and both neuronal and glial lineages, respectively (supplemental Fig. 3, available at www.jneurosci.org as supplemental material) (data not shown). Notably, when we quantified the number of glutamatergic $\left(\beta \mathrm{Gal}^{+} \mathrm{GABA}^{-} / \mathrm{DAPI}^{+}\right)$ and GABAergic $\left(\beta \mathrm{Gal}^{+} \mathrm{GABA}^{+} / \mathrm{DAPI}^{+}\right)$ neurons in Dbx1 ${ }^{\text {CRE }}$; Tau ${ }^{\text {GFPiresnlslac } Z}$ animals, we found that $95.57 \%$ of the glutamatergic population disappeared in adults, whereas the percentage of $D b x 1$-derived GABAergic cells did not significantly change (Fig. $6 K, L$ ).

We then tested whether the loss of Dbx1-derived glutamatergic cells was attributable to apoptotic cell death by coimmunostaining with activated-Caspase 3 $\left(\right.$ Caspase $\left.3^{\star}\right)$, a specific marker of apoptosis. We observed that in P0 Dbx $1^{C R E}$; Tau ${ }^{\text {GFPiresnlslac } Z}$ cerebral cortices, $34.9 \%$ of the total cells undergoing apoptotic cell death were $D b x 1$-derived $\left(\mathrm{ggal}^{+}\right.$ Caspase $3^{*+}$ ) (Fig. 6F-I). Moreover, we evaluated the proportion of neurons relative to the total dying cells in wild-type cortices using NeuN staining; $70.3 \%$ of the total apoptotic cells at $\mathrm{P} 0$ were $\mathrm{NeuN}^{+}$ $\left(\mathrm{NeuN}^{+}\right.$Caspase $^{{ }^{+}}{ }^{+}$), and therefore, $29.7 \%$ likely correspond to glial cells. Among the $\mathrm{NeuN}^{+}$population undergoing apoptosis, $50.3 \%$ were $D b x 1$-derived neurons $\left(\beta_{\mathrm{gal}}{ }^{+}\right.$ $\mathrm{NeuN}^{+}$Caspase $^{{ }^{+}}{ }^{+}$) (Fig. 6I,J).

We conclude that $D b x 1$-derived glutamatergic, but not GABAergic neurons, in the $\mathrm{CP}$ represent a transient population undergoing programmed cell death starting at $\mathrm{P} 0$ and account for $50 \%$ of the total apoptotic neurons in the $\mathrm{CP}$ at this stage.

\section{Reduction of cortical plate thickness} upon ablation of glutamatergic neurons derived from $D b x 1^{+}$progenitors at the PSB

To study the function of PSB-derived CP glutamatergic transient neurons, we performed genetic ablation using the $D b x 1^{\text {LoxP-stop-LoxP-DTA }}$ mouse line (Bielle et al., 2005) crossed with the E1-Ngn2/ CRE(iresGFP) transgenic line (Berger et al., 2004). In the telencephalon, CRE expression is restricted to subsets of ventral and lateral pallium progenitors at early stages and is not observed in the subpallium (Berger et al., 2004). TUNEL staining analysis revealed that dying cells are first detected at E11.5 mainly at the caudal PSB in the basal VZ/SVZ (Fig. 7A-D). A peak of cell death
E12.5 + 2 DIV
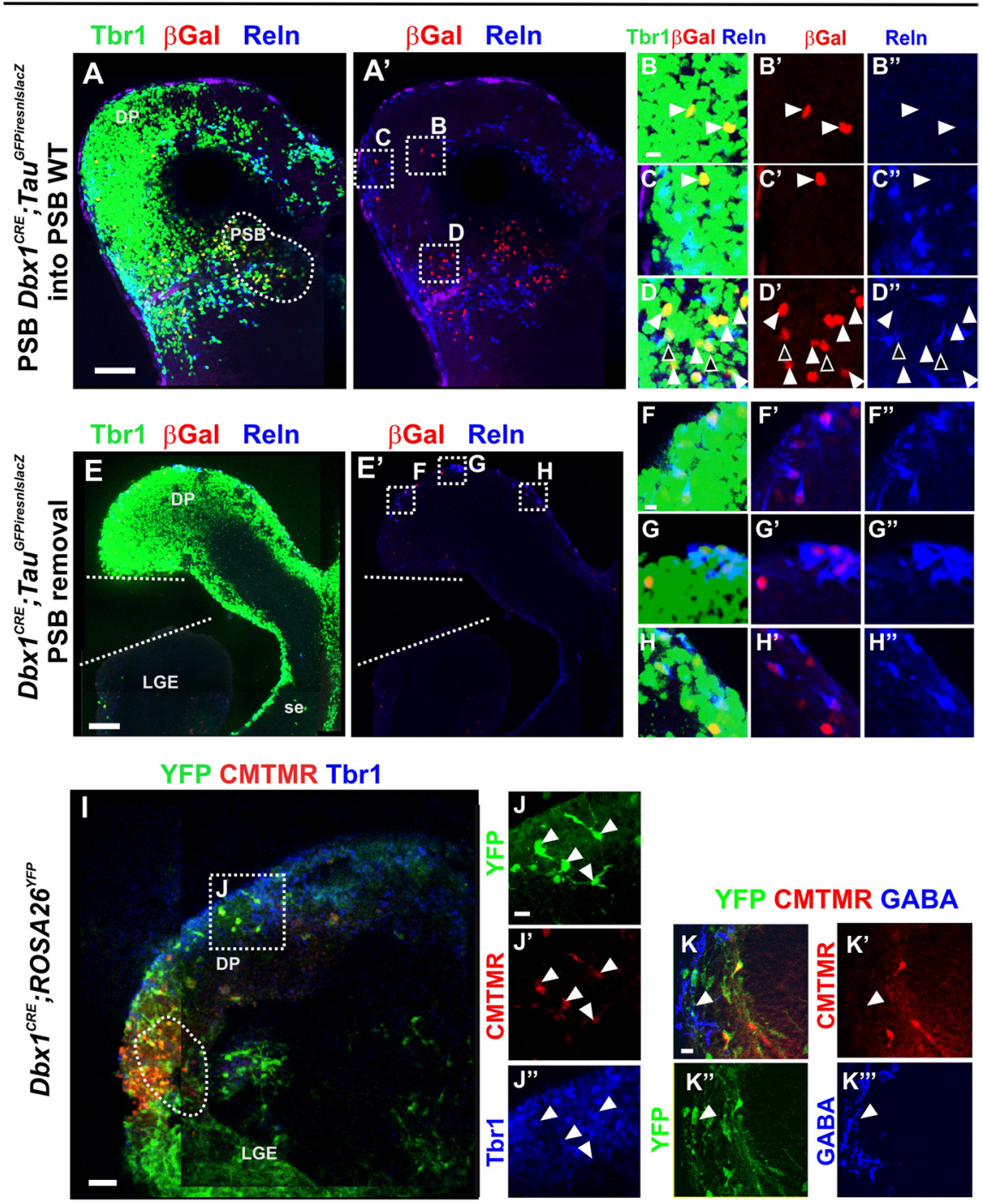

Figure 5. Dbx1-derived glutamatergic cells emerge from the PSB at E12.5 and invade the dorsal pallium by tangential migration.

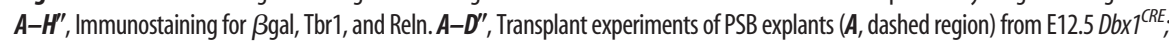
$\mathrm{Tau}^{\text {GFPiresnlslacZ }}$ animals into the PSB of E12.5 WT coronal brain slices and cultured for $2 \mathrm{DIV}$. $\beta \mathrm{Gal}{ }^{+} \mathrm{Tbr}{ }^{+}$Reln $^{-}$neurons migrate tangentially from the grafted explant into the dorsal pallium $\left(\boldsymbol{B}-\boldsymbol{C}^{\prime}\right)$ in addition to the lateral pallium $\left(\boldsymbol{D}-\boldsymbol{D}^{\prime \prime}\right)$ (white arrowheads). Migration of $\beta G \mathrm{G}^{+} \mathrm{Tbr}^{+}{ }^{+}$Reln ${ }^{+}$neurons is also detected in the lateral pallium $\left(\boldsymbol{D}-\boldsymbol{D}^{\prime}\right)$ (black arrowheads). $\boldsymbol{E}-\boldsymbol{H}^{\prime \prime}$, Removal of the PSB from E12.5 $D b \times 1^{\text {CRE }}$;Tau ${ }^{\text {GFPiresnlslacZ }}$ coronal slices shows that no $\beta G \mathrm{Gal}{ }^{+} \mathrm{Tbr}{ }^{+}$Reln ${ }^{-}$neurons are generated in the dorsal pallium or the septum. $\boldsymbol{F}-\boldsymbol{H}^{\prime}$, Only $\beta G \mathrm{Gal}^{+} \mathrm{Tbr}^{+}{ }^{+}$Reln ${ }^{+}$neurons are observed in the dorsal $\left(\boldsymbol{F}-\boldsymbol{G}^{\prime \prime}\right)$ or medial $\left(\boldsymbol{H}-\boldsymbol{H}^{\prime \prime}\right)$ pallium after 2 DIV, corresponding to the Cajal-Retzius cells generated by Dbx1-expressing cells at the septum and at the PSB earlier than E12.5. I- $\boldsymbol{K}^{\prime \prime \prime}$, A bead coated with CellTracker Orange (CMTMR) (dashed region at the PSB in $I$ ) was placed at the VZ of the PSB on $300 \mu \mathrm{m}$ coronal slices of E12.5 Dbx $1^{\text {CRE, }}$ ROSA26 ${ }^{Y F P}$ embryos and cultured for 2 DIV.I- $\boldsymbol{J}^{\prime \prime}$, Immunostaining for YFP and Tbr1 on $100 \mu \mathrm{m}$ sections shows glutamatergic Dbx 1 -derived cells in the dorsal pallium $\left(\boldsymbol{J}-\boldsymbol{J}^{\prime \prime}\right.$, white arrowheads) that have incorporated the CMTMR and thus originated from the PSB. $\boldsymbol{K}-\boldsymbol{K}^{\prime \prime \prime}$, Immunostaining for YFP and GABA on serial sections of the same experiment shows that none of the Dbx1-derived GABAergic cells in the pallium have incorporated the CMTMR confirming that the Dbx1-derived neurons migrating from the PSB are exclusively glutamatergic. DP, Dorsal pallium; LGE, lateral ganglionic eminence; se, septum. Scale bars: $A, E, I, 100 \mu \mathrm{m} ; \boldsymbol{B}, \boldsymbol{F}, \boldsymbol{K}, 10 \mu \mathrm{m}$.

was observed at the PSB at E12.5 and was almost undetectable by E14.5 in mutant animals (Fig. 7 I, J; supplemental Fig. 4, available at www.jneurosci.org as supplemental material), as expected from the dynamic of $D b x 1$ expression (Yun et al., 2001; Medina et al., 2004; Bielle et al., 2005). No cell death was observed in the cortex dorsally to the PSB at any embryonic stages tested (E11.5, E12.5, E14.5, E16.5, and E18.5) (Fig. 7G,H; supplemental Fig. 4, available at www.jneurosci.org as supplemental material) (data not shown). The effective ablation at the PSB was confirmed by the almost complete loss of Dbx1 protein at E12.5 (Fig. 7 E, F). In 

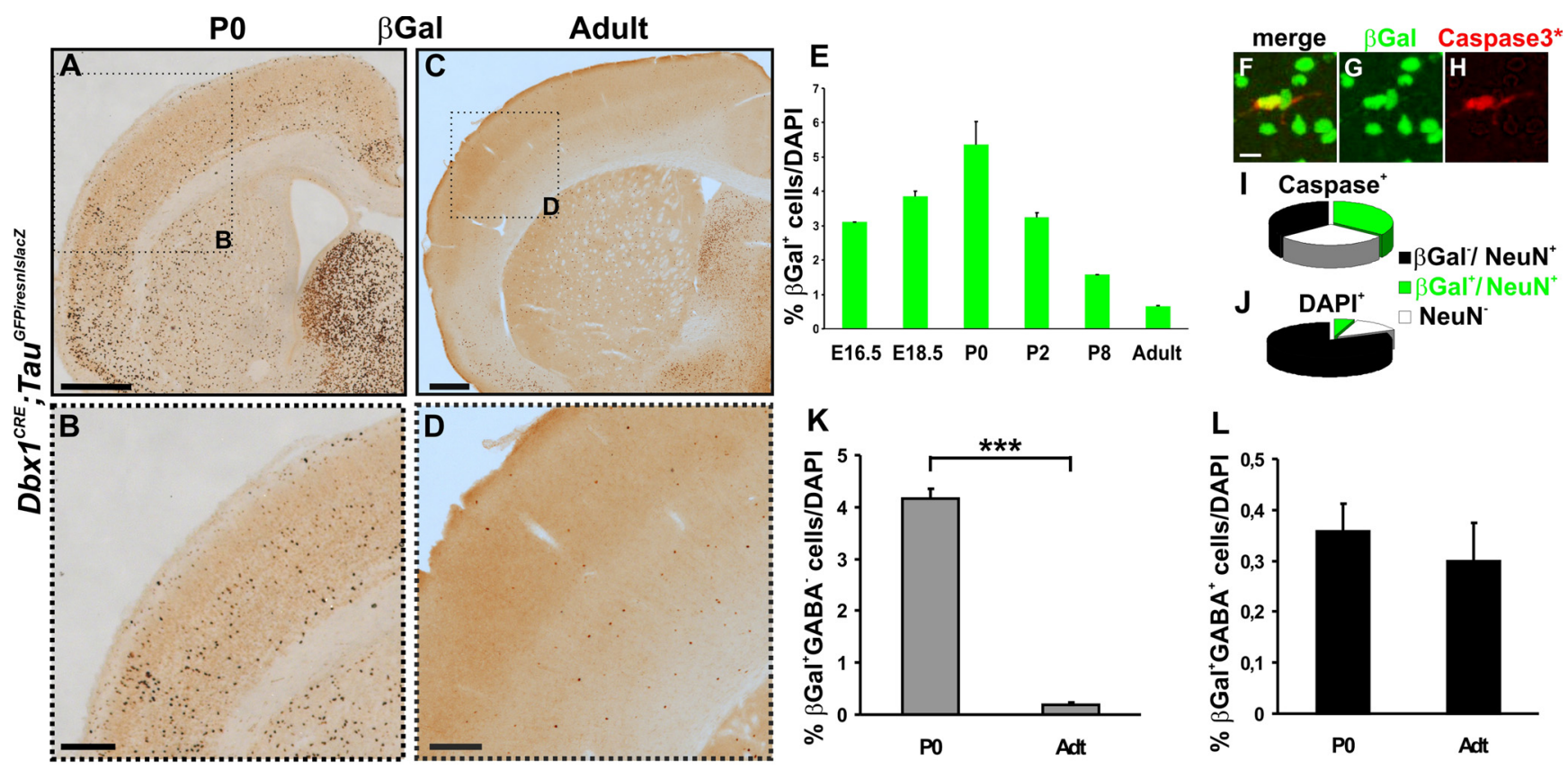

Figure 6. Glutamatergic $D b x 1$-derived cells undergo programmed cell death at birth. $A-D, \beta G$ al immunohistochemistry on coronal sections of Dbx $1^{\text {CRE. }}$ Tau ${ }^{G F P i r e s n / s l a c z}$ brains shows a strong decrease in the number of $\beta G a l^{+}$neurons in the adult neocortex $(\boldsymbol{C}, \boldsymbol{D})$, compared with neonatal $(\boldsymbol{A}, \boldsymbol{B})$ animals. $\boldsymbol{B}, \boldsymbol{D}$, High magnifications of boxed regions in $\boldsymbol{A}$ and $\boldsymbol{C}$, respectively. $\boldsymbol{E}$, Graph represents the percentage of $\beta \mathrm{Gal}^{+}$cells relative to DAPI ${ }^{+}$nuclei in the CP/layers II-VI from E16.5 to adulthood ( $n=3095$ at E16.5, $n=16,785$ at E18.5, $n=34,712$ at P0, $n=19,600$ at P2, $n=$ 9865 at P8, and $n=34,712$ in adults). $\boldsymbol{F}$-H, Activated-Caspase3 immunohistochemistry shows colocalization with $\beta G_{\text {Gal }}{ }^{+}$cells in P0 Dbx ${ }^{\text {CREF}}$; Tau ${ }^{\text {GFPiresnlslacZ }}$ cerebral cortices. I, Graph shows the proportion of $\beta \mathrm{Gal}^{+}$cells relative to Caspase3 ${ }^{*+}$ cells. $\beta \mathrm{Gal}^{+}$neurons represent $34.9 \pm 0.39 \%$ of total Caspase3* ${ }^{+}$cells $\left(n=111\right.$ of 316 cells) and $50.26 \pm 1.51 \%$ of NeuN ${ }^{+}$Caspase $3^{*}+$ neurons ( $n=97$ of 192 cells); $29.69 \pm 2.42 \%$ of total cortical Caspase $3^{*+}$ cells are NeuN ${ }^{-}$and, thus, are likely to represent glial cells $(n=83 / 275)$. J, NeuN staining on coronal sections of P0 cortices labels $87.13 \pm 2.33 \%$ of total DAPI ${ }^{+}$nuclei and $\beta \mathrm{Gal}^{+} \mathrm{NeuN}^{+}$cells represent $4.02 \pm 0.09 \%$ of the total NeuN ${ }^{+}$nuclei. $K, L_{\text {, Graphs represent the percentage of } \beta G a l}{ }^{+} \mathrm{GABA}^{-} / \mathrm{DAPI}{ }^{+}$ $(\boldsymbol{K})$ and $\beta \mathrm{Gal}^{+} \mathrm{GABA}^{+} / \mathrm{DAPI}^{+}(\boldsymbol{L})$ neurons at $\mathrm{P} 0$ and in adults. The percentage of $\beta \mathrm{Gal}{ }^{+} \mathrm{GABA}{ }^{-}$neurons is decreased by $95.6 \%$ between $\mathrm{P} 0$ and adult stages (from $4.16 \pm 0.18$ to $0.18 \pm$ $0.00063 \% ; n=15,037$ at $\mathrm{P} 0$ and $n=1000$ in adults; $p=0.00042$ ), whereas that of $\beta \mathrm{Gal}{ }^{+} \mathrm{GABA}^{+}$cells does not change (from $0.36 \pm 0.05$ to $0.29 \pm 0.027 \% ; n=1343$ at $\mathrm{P} 0$ and $n=1554$ in adults; $p=0.54794)$. Results are expressed as mean \pm SEM. ${ }^{* * *} p<0.001, t$ test. Scale bars: $\boldsymbol{A}, \boldsymbol{C}, 500 \mu \mathrm{m} ; \boldsymbol{B}, \boldsymbol{D}, 200 \mu \mathrm{m} ; \boldsymbol{F}, 10 \mu \mathrm{m}$.

addition, in $E 1-N g n 2 / C R E ; D b x 1^{D T A} ; D b x 1^{\text {nlsLacZ }}$ triple mutant compared with $D b x 1^{\text {LoxP-stop-LoxP-DTA }} ; D b x 1^{\text {nlsLacZ }}$ control embryos, we observed a 30-50\% decrease in the number of $\mathrm{XGal}^{+}$ cells in the PP/CP starting caudolaterally at E12.5 and progressing toward the rostrodorsal cortex at E14.5 (supplemental Fig. 4, available at www.jneurosci.org as supplemental material). To ensure that the ablation did not affect CR cells, we performed in situ hybridization for Reln and p73 mRNAs, which label CR cells (Cabrera-Socorro et al., 2007), between E11.5 and E14.5 in E1Ngn2/CRE;Dbx $1^{D T A}$ telencephalons and detected no difference in the number of CR neurons upon ablation (supplemental Fig. 5, available at www.jneurosci.org as supplemental material) (data not shown). We also observed no changes in interneuron number and/or distribution at E12.5 using Calbindin staining (supplemental Fig. 5, available at www.jneurosci.org as supplemental material). Last, the ablation did not lead to defects in the expression of signaling molecules at the PSB, namely Tgf $\alpha$, Sfrp2, and $W n t 7 b$, or in the establishment of the PSB as shown by the similar domains of Ngn2 and $D l x 1$ expression (supplemental Fig. 5, available at www. jneurosci.org as supplemental material). We conclude that E1Ngn2/CRE; $D b x 1^{D T A}$ embryos show a specific ablation of $D b x 1$ expressing progenitors at the PSB and of $30-50 \%$ of CP glutamatergic transient neurons without affecting CR cells or subpallially derived interneuron generation and migration.

We then analyzed the mutant phenotype at perinatal stages before the onset of death of the transient $D b \times 1$-derived CP neurons. Mutant brains appeared slightly smaller, and we observed an overall $18-22 \%$ reduction in thickness of the cortical plate at all RC and $\mathrm{ML}$ levels of the neocortex using Nissl staining at E18.5 to P2 (Fig. 7K-R) (data not shown). The thickness of the CP seemed to be affected in all cortical areas in a similar manner upon $D b x 1$-expressing progenitor ablation. Cell density was similar between control and mutant brains $\left(14,911 \pm 4380\right.$ cells $/ \mathrm{mm}^{2}$ in controls and $13,000 \pm 3668$ cells $/ \mathrm{mm}^{2}$ in mutants; $p=0.33$ ) and no changes in density of GABA staining was observed at P2 (data not shown).

Together, these results show that genetic ablation of Dbx1derived CP transient neurons generated at the PSB leads to a decrease in cell numbers throughout the neocortex. Since this neuronal population represents $<5 \%$ of cortical cells, together our data strongly suggest that they play a crucial role in corticogenesis at a distance from their generation site in a non-cellautonomous manner.

\section{Discussion}

We have identified a novel transient population of glutamatergic neurons generated from $D b x 1$-expressing progenitors at the PSB mostly at E12.5. This population invades the PP/CP by tangential migration with a caudolateral-to-rostromedial progression starting at E12.5 and redistributes homogeneously in the cortical plate along the RC and ML axis afterward. Beginning at birth, CP Dbx1-derived neurons undergo PCD and massively disappear during the first postnatal week. Specific ablation of this cell population leads to a reduction in $\mathrm{CP}$ thickness at neonatal stages, suggesting that they play a crucial role in cortical growth at long distance from their site of origin in a non-cell-autonomous manner.

\section{Focal origins of glutamatergic cortical neurons and tangential migration}

We described by genetic tracing the progressive tangential dispersion of a subpopulation of glutamatergic neurons arising at 
early stages of PP/CP formation from a focal pallial progenitor domain at the PSB. Although previously thought to be a feature of GABAergic interneurons (Marín and Rubenstein, 2003), tangential migration of glutamatergic neurons has now been reported for several populations during development (Walsh and Cepko, 1992; O’Rourke et al., 1995; Rakic, 1995), including Satb $2^{+}$and CajalRetzius neurons (Takiguchi-Hayashi et al., 2004; Bielle et al., 2005; Britanova et al., 2006; Yoshida et al., 2006). At least two of the glutamatergic transient neurons forming the preplate/early CP, CR and Dbx1-derived CP neurons, have now been shown by genetic tracing to be generated at the borders of the developing pallium. Subplate and pioneer cells are also thought to derive in humans and rodents, respectively, from extraneocortical territories (Meyer et al., 1998; Morante-Oria et al., 2003; Bystron et al., 2006). Our results support the notion that tangential dispersion of glutamatergic postmitotic neurons is more represented than previously thought and is used by many of the earliest-born neurons in the developing pallium. Moreover, our results show that Dbx1-expressing progenitors at the PSB sequentially generate neurons expressing the appropriate sequence of layer specific markers described for successive offspring of cortical progenitors (Molyneaux et al., 2007). Thus, despite their focal origin and long-range migration, Dbx1-derived CP neurons position into the $\mathrm{CP}$ according to their birthdates, supporting the hypothesis of intrinsic cues governing laminar fate (McConnell and Kaznowski, 1991; Desai and McConnell, 2000).

We have shown that CP transient neurons reach the cortex by migrating along the SP and IZ/SVZ but appear to avoid the MZ. In the IZ, they intermingle with GABAergic neurons and the onset of invasion of pallial territories also strongly parallels that of inhibitory interneurons. This suggests that similar molecular mechanisms might govern tangential migration in the IZ for both GABAergic and $\mathrm{CP}$ transient neurons. Indeed, in the $\mathrm{MZ}$, similar cues have been shown to control the migration of GABAergic and CR cells, namely the CXCL12/CXCR4 pathway (Stumm et al., 2003; Borrell and Marín, 2006; Paredes et al., 2006). However, in contrast to GABAergic and CR neurons, CP transient neurons do not appear to be prevented to enter the CP. Moreover, in contrast to CR subtypes, which distribute in specific proportions in pallial regions and have been suggested to respond to contact-inhibitory interactions (Bielle et al., 2005; Borrell and Marín, 2006), CP transient neurons distribute homogeneously in all developing cortical regions. These results suggest that they may respond dif-
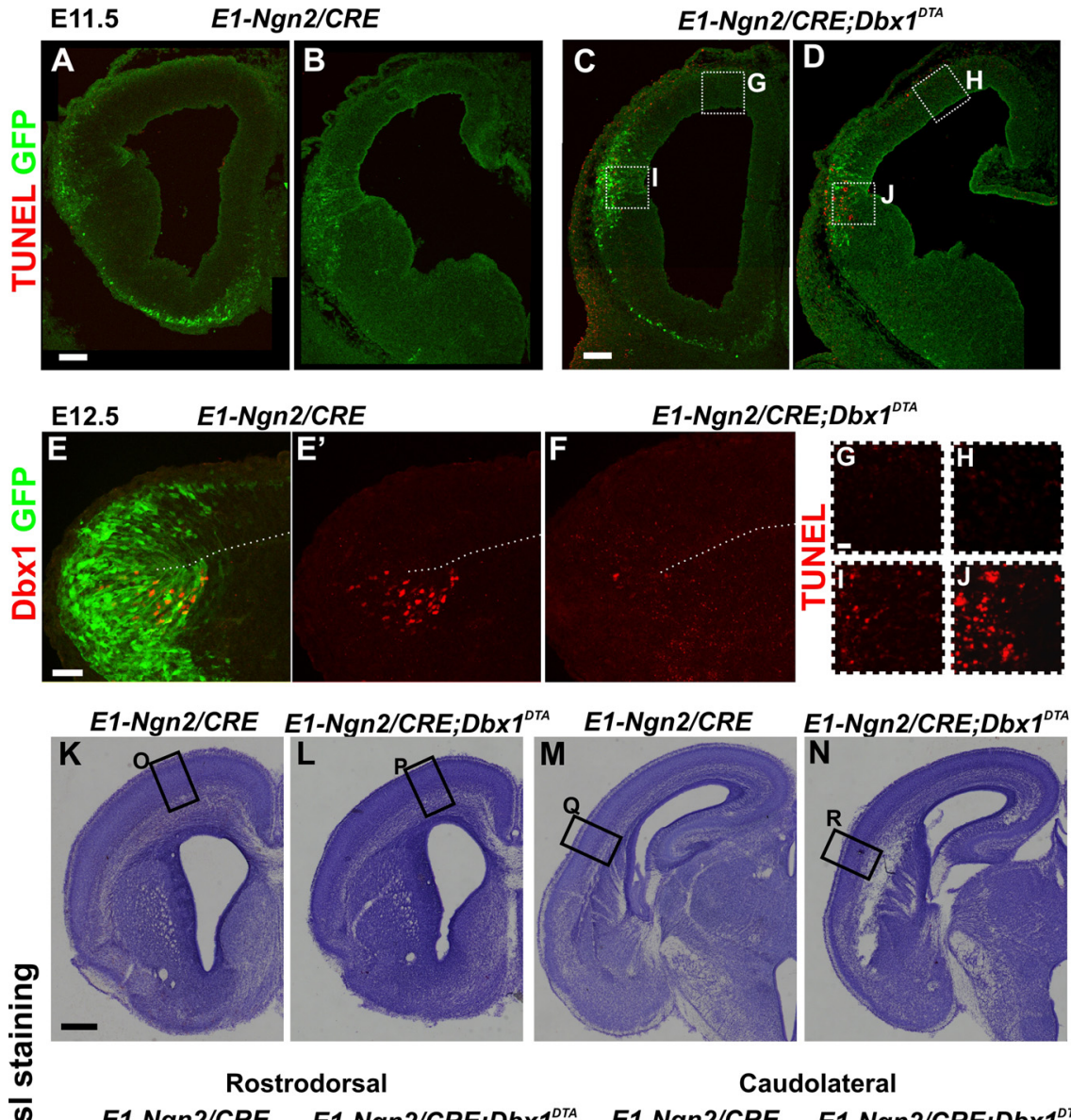

E1-Ngn2/CRE;DbX1 $1^{\text {DTA }}$
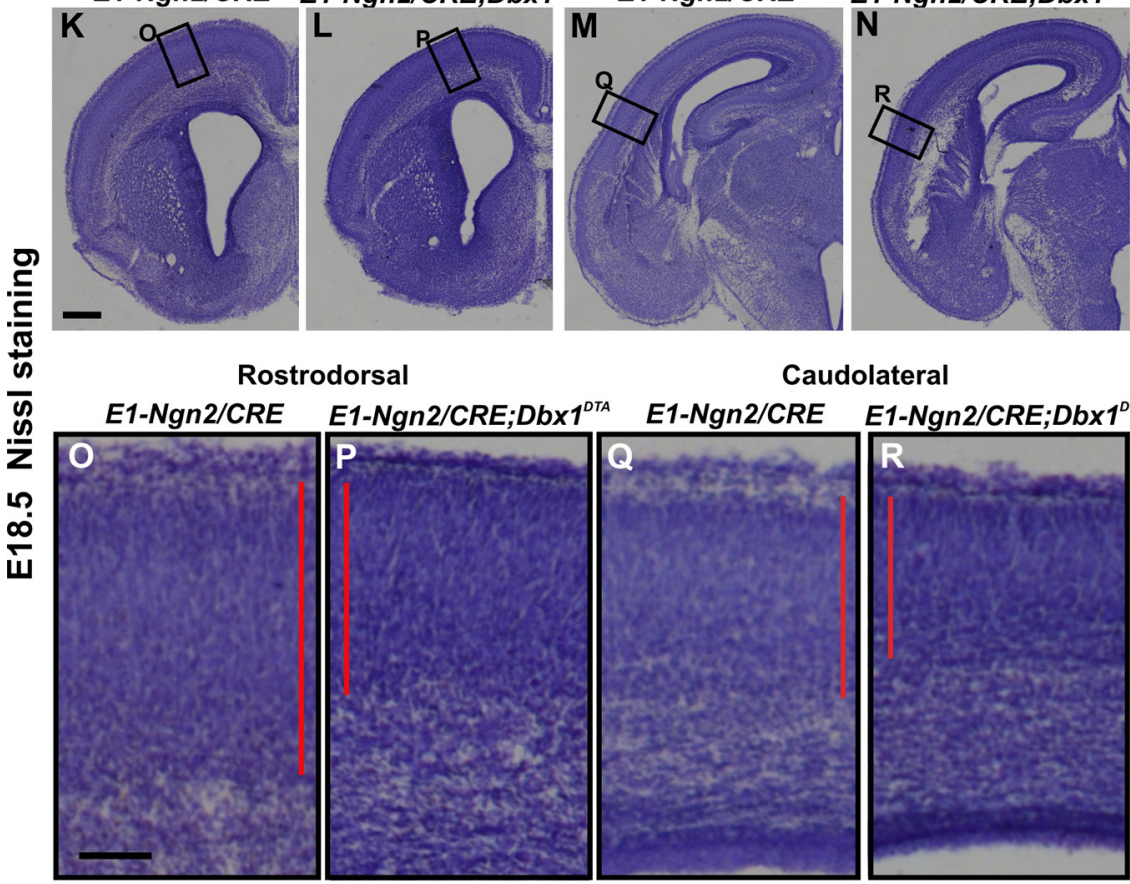

Caudolateral

Figure 7. Decrease of cortical plate thickness in E1-Ngn2/CRE;Dbx $1^{D T A}$ animals upon ablation of CP transient cells. $A-D, G-J$ TUNEL and GFP staining of E11.5 E1-Ngn2/CRE(iresGFP) control $(\boldsymbol{A}, \boldsymbol{B})$ and E1-Ngn2/CRE;Dbx $1^{\text {DTA }}(\boldsymbol{C}, \boldsymbol{D})$ telencephalons. $\mathbf{G}-\boldsymbol{J}$, High magnifications of boxed regions in $\boldsymbol{C}$ and $\boldsymbol{D}$. More TUNEL ${ }^{+}$cells are detected at the PSB caudally $(\boldsymbol{J})$ than rostrally $(\boldsymbol{I})$ in mutants, whereas no cell death is observed in the dorsolateral pallium $(\boldsymbol{G}, \boldsymbol{H})$ and control telencephalons. $\boldsymbol{E}, \boldsymbol{F}$, Immunohistochemistry for GFP and Dbx1 on E12.5 embryos showing that the E1-Ngn2/CRE(iresGFP) enhancer is expressed in all Dbx ${ }^{+}$progenitors at the PSB in control animals $\left(\boldsymbol{E}, \boldsymbol{E}^{\prime}\right)$. The number of Dbx ${ }^{+}$progenitors is dramatically reduced in $E 1-N g n 2 / C R E ; D b \times 1^{D T A}$ animals at the PSB (compare $\left.\boldsymbol{E}^{\prime}, \boldsymbol{F}\right) . \boldsymbol{K}-\boldsymbol{R}$, Nissl staining on coronal sections of E18.5 control $(\boldsymbol{K}, \boldsymbol{M}, \mathbf{O}, \mathbf{Q})$ and E1-Ngn2/CRE;Dbx $1^{D T A}$ mutant $(\boldsymbol{L}, \boldsymbol{N}, \boldsymbol{P}, \boldsymbol{R})$ cortices at rostrodorsal $(\boldsymbol{K}, L, \mathbf{O}, \boldsymbol{P})$ and caudolateral $(M, N, \mathbf{Q}, \boldsymbol{R})$ levels showing a decrease in $(P$ thickness in mutant compared with control animals. Scale bars: $\boldsymbol{K}, 250 \mu \mathrm{m} ; \boldsymbol{A}, \mathbf{C}, 100 \mu \mathrm{m} ; \boldsymbol{E}, \mathbf{0}, 50 \mu \mathrm{m} ; \mathbf{G}, 20 \mu \mathrm{m}$.

ferently to cues that govern the invasion of cortical territories by other tangentially migrating neurons.

Early preplate neurons, pioneer functions, and programmed cell death in cortical development

Specific subpopulations of neurons have been suggested to undergo PCD in the cerebral cortex such as CR and SP cells and hippocampal interneurons (Supèr et al., 1998). PCD is a well known developmental event and cortical cell death has been shown to involve up to $30 \%$ 
of the cells and to mainly occur around P4-P6 in superficial layers (Verney et al., 2000). Indeed, the peak of PCD is commonly associated with increased sensory activity corresponding to the period of synaptogenesis and axonal outgrowth/targeting (Buss et al., 2006; Heck et al., 2008; Morishita and Hensch, 2008). However, only recent genetic tracing has allowed the life span of specific cell populations, namely CR neurons (Bielle et al., 2005) and oligodendrocytes (Kessaris et al., 2006), to be assessed. We describe here that glutamatergic, but not GABAergic, Dbxl-derived neurons populating the CP constitute an early-born population that undergoes almost complete PCD at birth and represents $50 \%$ of the total dying neurons at this stage. Our results describe for the first time precise kinetics of massive neuronal death in a specific, and previously unidentified, glutamatergic population in the $\mathrm{CP}$ and attribute a function to it in regulating cortical growth. Notably, Dbxl-derived CP neurons death begins before the peak of activity-dependent PCD and coincides with the end of the proliferation of progenitors during development (Caviness et al., 1995). Together with the role of CR cells in controlling radial migration and that of SP cells in axonal pathfinding (Supèr et al., 1998), our results strongly suggest that the early $\mathrm{PP} / \mathrm{CP}$ are populated by many transient neurons, which orchestrate crucial steps in the construction of the cerebral cortex architecture. Notably, processes of proliferation, migration, and axonal pathfinding are strongly reduced or extinguished in the mature cortex. Thus, the disappearance of transient cell/structures might be crucial for the accomplishment of development, and, indeed, their perdurance has been described in pathological conditions (Blümcke et al., 2002; Kostović and Judas, 2007). Interestingly, at least two of these transient populations, CR and CP transient neurons, are sequentially born at early stages (E10-E12) from Dbx1-expressing progenitors at the PSB. Hence, these early generated neurons might be intrinsically determined from their early birthdate and their site of origin to a short transient life span during which they perform specific developmental functions.

Our results strongly suggest that Dbx1-derived CP transient glutamatergic neurons function in a non-cell-autonomous manner since they only represent $<5 \%$ of cortical cells and DTA-mediated ablation is strictly cell autonomous. Our data open the question as to whether CP transient neurons might affect corticogenesis while invading the pallium or at later stages of development when positioned in the $\mathrm{CP}$ before undergoing PCD. The distribution of CP transient neurons in all cortical territories by E14.5 together with the homogeneous defects of cortical thickness along the RC axis and the absence of an increase in cell death in E1-Ngn2/CRE;Dbx $1^{D T A}$ mutants suggest that $\mathrm{CP}$ transient neurons might affect progenitors' proliferation/differentiation but not survival at midcorticogenesis. Indeed, a feedback control from the postmitotic compartment on the VZ has been suggested to affect the generation of later-born neurons (Polleux et al., 1998; Viti et al., 2003; Dehay and Kennedy, 2007) as well as the switch from neurogenesis to gliogenesis (Seuntjens et al., 2009). Nevertheless, the final positioning of CP transient neurons into the $\mathrm{CP}$ is also consistent with a function for $\mathrm{CP}$ transient neurons at late stages of development, such as in the establishment of transient connections.

\section{Acquisition of $D b x 1$-derived transient neurons at the PSB and the evolution of the neocortex}

The PSB has been the center of debate in studies on cortical evolution and the acquisition of a new progenitor domain in the VP at the PSB or of migration trajectories from this domain have been proposed to play a crucial role in the "complexification" of the claustro-amygdaloid complex and of the lateral pallium (LP) in mammals (Molnár and Butler, 2002; Medina et al., 2004).
However, its role in neocortical evolution is still not yet established. Based on analogy of connectivity, Karten (1997) suggested that the redistribution by tangential migration of cells generated by the DVR (dorsal ventricular ridge) domain, a derivative of the $\mathrm{VP} / \mathrm{LP}$ in birds and reptiles, contributed to form the neocortex. However, until recently, tangential migration of glutamatergic cells from the VP/PSB toward the dorsal pallium was not demonstrated in mammals and was further excluded to occur in sauropsids (Métin et al., 2007).

We now have shown that tangential migration of glutamatergic neurons from the borders of the developing pallium (VP/PSB and pallial septum) occurs in mice for CR subtypes, populating the MZ between E10.5 and E11.5 (Bielle et al., 2005), and CP transient neurons invading the PP/CP between E12.5 and E14.5. CR neurons act as mediators of cortical patterning and arealization (Griveau et al., 2010), and thus are involved in tangential growth of cortical areas, and the amplification of the number of Reln ${ }^{+}$cells has been shown in mammals (Bar et al., 2000; Cabrera-Socorro et al., 2007). Our results suggest that CP transient neurons are required for radial growth of the neocortex. Since $D b x 1$ is not expressed at the PSB in chicks (Bielle et al., 2005), we suggest that together our results might reconcile theories of cortical evolution by providing support for the acquisition of new progenitor domain(s) at the PSB, or antihem, and of tangentially migrating glutamatergic "signaling" cells in mammals. These transient neurons, by participating in controlling growth from extraneocortical origins through cell migration, could be one of the evolutionary steps to pattern large structure such as the cerebral cortex and increase vertebrate brain complexity (Supèr and Uylings, 2001).

\section{References}

Bar I, Lambert de Rouvroit C, Goffinet AM (2000) The evolution of cortical development. An hypothesis based on the role of the Reelin signaling pathway. Trends Neurosci 23:633-638.

Berger J, Eckert S, Scardigli R, Guillemot F, Gruss P, Stoykova A (2004) E1-Ngn2/Cre is a new line for regional activation of Cre recombinase in the developing CNS. Genesis 40:195-199.

Berry M, Rogers AW, Eayrs JT (1964) Pattern of cell migration during cortical histogenesis. Nature 203:591-593.

Bielle F, Griveau A, Narboux-Nême N, Vigneau S, Sigrist M, Arber S, Wassef M, Pierani A (2005) Multiple origins of Cajal-Retzius cells at the borders of the developing pallium. Nat Neurosci 8:1002-1012.

Blümcke I, Thom M, Wiestler OD (2002) Ammon's horn sclerosis: a maldevelopmental disorder associated with temporal lobe epilepsy. Brain Pathol 12:199-211.

Borrell V, Marín O (2006) Meninges control tangential migration of hemderived Cajal-Retzius cells via CXCL12/CXCR4 signaling. Nat Neurosci 9:1284-1293.

Britanova O, Alifragis P, Junek S, Jones K, Gruss P, Tarabykin V (2006) A novel mode of tangential migration of cortical projection neurons. Dev Biol 298:299-311.

Buss RR, Sun W, Oppenheim RW (2006) Adaptive roles of programmed cell death during nervous system development. Annu Rev Neurosci 29:1-35.

Bystron I, Rakic P, Molnár Z, Blakemore C (2006) The first neurons of the human cerebral cortex. Nat Neurosci 9:880-886.

Cabrera-Socorro A, Hernandez-Acosta NC, Gonzalez-Gomez M, Meyer G (2007) Comparative aspects of p73 and Reelin expression in CajalRetzius cells and the cortical hem in lizard, mouse and human. Brain Res 1132:59-70.

Caviness VS Jr, Takahashi T, Nowakowski RS (1995) Numbers, time and neocortical neuronogenesis: a general developmental and evolutionary model. Trends Neurosci 18:379-383.

Dehay C, Kennedy H (2007) Cell-cycle control and cortical development. Nat Rev Neurosci 8:438-450.

Dehay C, Savatier P, Cortay V, Kennedy H (2001) Cell-cycle kinetics of neocortical precursors are influenced by embryonic thalamic axons. J Neurosci 21:201-214. 
Desai AR, McConnell SK (2000) Progressive restriction in fate potential by neural progenitors during cerebral cortical development. Development 127:2863-2872.

Dubreuil V, Ramanantsoa N, Trochet D, Vaubourg V, Amiel J, Gallego J, Brunet JF, Goridis C (2008) A human mutation in Phox2b causes lack of $\mathrm{CO}_{2}$ chemosensitivity, fatal central apnea, and specific loss of parafacial neurons. Proc Natl Acad Sci U S A 105:1067-1072.

Englund C, Fink A, Lau C, Pham D, Daza RA, Bulfone A, Kowalczyk T, Hevner RF (2005) Pax6, Tbr2, and Tbr1 are expressed sequentially by radial glia, intermediate progenitor cells, and postmitotic neurons in developing neocortex. J Neurosci 25:247-251.

Ferrer I, Bernet E, Soriano E, del Rio T, Fonseca M (1990) Naturally occurring cell death in the cerebral cortex of the rat and removal of dead cells by transitory phagocytes. Neuroscience 39:451-458.

Griveau A, Borello U, Causeret F, Tissir F, Boggetto N, Karaz S, Pierani A (2010) A novel role for Dbx1-derived Cajal-Retzius cells in early regionalization of the cerebral cortical neuroepithelium. PloS Biol 8:e1000440.

Guillemot F (2005) Cellular and molecular control of neurogenesis in the mammalian telencephalon. Curr Opin Cell Biol 17:639-647.

Haydar TF, Kuan CY, Flavell RA, Rakic P (1999) The role of cell death in regulating the size and shape of the mammalian forebrain. Cereb Cortex 9:621-626.

Heck N, Golbs A, Riedemann T, Sun JJ, Lessmann V, Luhmann HJ (2008) Activity-dependent regulation of neuronal apoptosis in neonatal mouse cerebral cortex. Cereb Cortex 18:1335-1349.

Hippenmeyer S, Vrieseling E, Sigrist M, Portmann T, Laengle C, Ladle DR, Arber S (2005) A developmental switch in the response of DRG neurons to ETS transcription factor signaling. PLoS Biol 3:e159.

Hirata T, Li P, Lanuza GM, Cocas LA, Huntsman MM, Corbin JG (2009) Identification of distinct telencephalic progenitor pools for neuronal diversity in the amygdala. Nat Neurosci 12:141-149.

Huh Y, Kim C, Lee W, Kim J, Ahn H (1997) Age-related change in the neuropeptide $\mathrm{Y}$ and NADPH-diaphorase-positive neurons in the cerebral cortex and striatum of aged rats. Neurosci Lett 223:157-160.

Innocenti GM, Price DJ (2005) Exuberance in the development of cortical networks. Nat Rev Neurosci 6:955-965.

Karten HJ (1997) Evolutionary developmental biology meets the brain: the origins of mammalian cortex. Proc Natl Acad Sci U S A 94:2800-2804.

Kessaris N, Fogarty M, Iannarelli P, Grist M, Wegner M, Richardson WD (2006) Competing waves of oligodendrocytes in the forebrain and postnatal elimination of an embryonic lineage. Nat Neurosci 9:173-179.

Kostović I, Judas M (2007) Transient patterns of cortical lamination during prenatal life: do they have implications for treatment? Neurosci Biobehav Rev 31:1157-1168.

Kriegstein AR, Noctor SC (2004) Patterns of neuronal migration in the embryonic cortex. Trends Neurosci 27:392-399.

Kriegstein A, Noctor S, Martínez-Cerdeño V (2006) Patterns of neural stem and progenitor cell division may underlie evolutionary cortical expansion. Nat Rev Neurosci 7:883-890.

Livak KJ, Schmittgen TD (2001) Analysis of relative gene expression data using real-time quantitative PCR and the $2^{-\Delta \Delta C(\mathrm{~T})}$ method. Methods 25:402-408.

Marín O, Rubenstein JL (2003) Cell migration in the forebrain. Annu Rev Neurosci 26:441-483.

Marín-Padilla M (1998) Cajal-Retzius cells and the development of the neocortex. Trends Neurosci 21:64-71.

McConnell SK, Kaznowski CE (1991) Cell cycle dependence of laminar determination in developing neocortex. Science 254:282-285.

Medina L, Legaz I, González G, De Castro F, Rubenstein JL, Puelles L (2004) Expression of Dbxl, Neurogenin 2, Semaphorin 5A, Cadherin 8, and Emx1 distinguish ventral and lateral pallial histogenetic divisions in the developing mouse claustroamygdaloid complex. J Comp Neurol 474:504-523.

Métin C, Alvarez C, Moudoux D, Vitalis T, Pieau C, Molnár Z (2007) Conserved pattern of tangential neuronal migration during forebrain development. Development 134:2815-2827.

Meyer G, Soria JM, Martínez-Galán JR, Martín-Clemente B, Fairén A (1998) Different origins and developmental histories of transient neurons in the marginal zone of the fetal and neonatal rat cortex. J Comp Neurol 397:493-518.

Mitrovic N, Schachner M (1996) Transient expression of NADPH diaphorase activity in the mouse whisker to barrel field pathway. J Neurocytol 25:429-437.
Molnár Z, Butler AB (2002) The corticostriatal junction: a crucial region for forebrain development and evolution. Bioessays 24:530-541.

Molyneaux BJ, Arlotta P, Menezes JR, Macklis JD (2007) Neuronal subtype specification in the cerebral cortex. Nat Rev Neurosci 8:427-437.

Morante-Oria J, Carleton A, Ortino B, Kremer EJ, Fairén A, Lledo PM (2003) Subpallial origin of a population of projecting pioneer neurons during corticogenesis. Proc Natl Acad Sci U S A 100:12468-12473.

Morishita H, Hensch TK (2008) Critical period revisited: impact on vision. Curr Opin Neurobiol 18:101-107.

O'Leary DD, Chou SJ, Sahara S (2007) Area patterning of the mammalian cortex. Neuron 56:252-269.

O’Rourke NA, Sullivan DP, Kaznowski CE, Jacobs AA, McConnell SK (1995) Tangential migration of neurons in the developing cerebral cortex. Development 121:2165-2176.

Paredes MF, Li G, Berger O, Baraban SC, Pleasure SJ (2006) Stromalderived factor-1 (CXCL12) regulates laminar position of Cajal-Retzius cells in normal and dysplastic brains. J Neurosci 26:9404-9412.

Pierani A, Moran-Rivard L, Sunshine MJ, Littman DR, Goulding M, Jessell TM (2001) Control of interneuron fate in the developing spinal cord by the progenitor homeodomain protein Dbx1. Neuron 29:367-384.

Polleux F, Dehay C, Kennedy H (1998) Neurogenesis and commitment of corticospinal neurons in reeler. J Neurosci 18:9910-9923.

Rakic P (1972) Mode of cell migration to the superficial layers of fetal monkey neocortex. J Comp Neurol 145:61-83.

Rakic P (1974) Neurons in rhesus monkey visual cortex: systematic relation between time of origin and eventual disposition. Science 183:425-427.

Rakic P (1995) Radial versus tangential migration of neuronal clones in the developing cerebral cortex. Proc Natl Acad Sci U S A 92:11323-11327.

Rozen S, Skaletsky H (2000) Primer3 on the WWW for general users and for biologist programmers. Methods Mol Biol 132:365-386.

Sansom SN, Hébert JM, Thammongkol U, Smith J, Nisbet G, Surani MA, McConnell SK, Livesey FJ (2005) Genomic characterisation of a Fgf-regulated gradient-based neocortical protomap. Development 132:3947-3961.

Seuntjens E, Nityanandam A, Miquelajauregui A, Debruyn J, Stryjewska A, Goebbels S, Nave KA, Huylebroeck D, Tarabykin V (2009) Sip1 regulates sequential fate decisions by feedback signaling from postmitotic neurons to progenitors. Nat Neurosci 12:1373-1380.

Spandidos A, Wang X, Wang H, Seed B (2010) PrimerBank: a resource of human and mouse PCR primer pairs for gene expression detection and quantification. Nucleic Acids Res 38:D792-D799.

Srinivas S, Watanabe T, Lin CS, William CM, Tanabe Y, Jessell TM, Costantini F (2001) Cre reporter strains produced by targeted insertion of EYFP and ECFP into the ROSA26 locus. BMC Dev Biol 1:4.

Stumm RK, Zhou C, Ara T, Lazarini F, Dubois-Dalcq M, Nagasawa T, Höllt V, Schulz S (2003) CXCR4 regulates interneuron migration in the developing neocortex. J Neurosci 23:5123-5130.

Supèr H, Uylings HB (2001) The early differentiation of the neocortex: a hypothesis on neocortical evolution. Cereb Cortex 11:1101-1109.

Supèr H, Soriano E, Uylings HB (1998) The functions of the preplate in development and evolution of the neocortex and hippocampus. Brain Res Brain Res Rev 27:40-64.

Takiguchi-Hayashi K, Sekiguchi M, Ashigaki S, Takamatsu M, Hasegawa H, Suzuki-Migishima R, Yokoyama M, Nakanishi S, Tanabe Y (2004) Generation of reelin-positive marginal zone cells from the caudomedial wall of telencephalic vesicles. J Neurosci 24:2286-2295.

Verney C, Takahashi T, Bhide PG, Nowakowski RS, Caviness VS Jr (2000) Independent controls for neocortical neuron production and histogenetic cell death. Dev Neurosci 22:125-138.

Viti J, Gulacsi A, Lillien L (2003) Wnt regulation of progenitor maturation in the cortex depends on Shh or fibroblast growth factor 2. J Neurosci 23:5919-5927.

Walsh C, Cepko CL (1992) Widespread dispersion of neuronal clones across functional regions of the cerebral cortex. Science 255:434-440.

Yoshida M, Assimacopoulos S, Jones KR, Grove EA (2006) Massive loss of Cajal-Retzius cells does not disrupt neocortical layer order. Development 133:537-545.

Yun K, Potter S, Rubenstein JL (2001) Gsh2 and Pax6 play complementary roles in dorsoventral patterning of the mammalian telencephalon. Development 128:193-205.

Zecevic N, Rakic P (2001) Development of layer I neurons in the primate cerebral cortex. J Neurosci 21:5607-5619. 